\title{
On the link between the subseasonal evolution of the North Atlantic Oscillation and East Asian climate
}

\author{
Massimo A. Bollasina ${ }^{1} \cdot$ Gabriele Messori $^{2,3}$ (D
}

Received: 21 June 2017 / Accepted: 14 January 2018 / Published online: 30 January 2018

(c) The Author(s) 2018. This article is an open access publication

\begin{abstract}
We analyse the impact of the North Atlantic Oscillation (NAO) on the climate of East Asia at subseasonal time scales during both winter and summer. These teleconections have mainly been investigated at seasonal and longer time scales, while higher-frequency links are largely unexplored. The NAO is defined using extended empirical orthogonal functions on pentad-mean observations, which allows to elucidate the oscillation's spatial and temporal evolution and clearly separate the development and decay phases. The downstream dynamical imprint and associated temperature and precipitation anomalies are quantified by means of a linear regression analysis. It is shown that the NAO generates a significant climate response over East Asia during both the dry and wet seasons, whose spatial pattern is highly dependent on the phase of the NAO's life cycle. Temperature and precipitation anomalies develop concurrently with the NAO mature phase, and reach maximum amplitude 5-10 days later. These are shown to be systematically related to mid and high-latitude teleconnections across the Eurasian continent via eastward-propagating quasi-stationary Rossby waves instigated over the Atlantic and terminating in the northeastern Pacific. These findings underscore the importance of rapidly evolving dynamical processes in governing the NAO's downstream impacts and teleconnections with East Asia.
\end{abstract}

Keywords North Atlantic Oscillation · East Asian monsoon · Teleconnections · Precipitation · Extended empirical orthogonal functions

\section{Introduction}

The annual cycle of East Asian climate is dominated by a seasonal reversal of the winds and a clearly defined rainy season, both key features of the East Asian monsoon (EAM). During boreal summer, the large-scale moisture-laden southwesterlies associated with the Asian monsoon flow along with the southeasterlies associated with the western Pacific

Electronic supplementary material The online version of this article (https://doi.org/10.1007/s00382-018-4095-5) contains supplementary material, which is available to authorized users.

Gabriele Messori

gabriele.messori@misu.su.se

1 School of GeoSciences, University of Edinburgh, Edinburgh, UK

2 Met Office Hadley Centre, Exeter, UK

3 Present Address: Department of Meteorology and Bolin Centre for Climate Science, Stockholm University, Svante Arrhenius Väg 16c, 10691 Stockholm, Sweden subtropical high supply water vapor to the East Asian summer monsoon (EASM) and bring abundant precipitation across the region (e.g., Zhou et al. 2009). During the winter months the dominance of the continental Siberian High favours low-level cold northeasterlies, associated with the East Asian winter monsoon (EAWM). Variations in either of these components can exert large impacts on economy and society of this densely populated region, such as those due to extreme cold outbreaks and severe flooding (e.g., Huang et al. 2012). Additionally, given the near-global footprint of the Asian monsoon system, of which the EAM is a major component, the climate impacts may extend well beyond the regional scale (e.g., Ding and Chan 2005).

The EAM presents considerable variability on multiple temporal and spatial scales, driven by a variety of local and remote factors (e.g., Chang 2004; Chang et al. 2006; Ding and Chan 2005, among others). In contrast to other monsoons (e.g., the South Asian monsoon), variations of the EAM are controlled by tropical as well as extratropical disturbances (e.g., Wang et al. 2003). 
One of the key drivers of the EAM seasonal to interannual variability is the El Niño-Southern Oscillation (ENSO; e.g., Wu et al. 2003); on decadal scales, ENSO's influence on the monsoon can also be heavily modulated by the Pacific Decadal Oscillation (PDO; Feng et al. 2014; Song and Zhou 2015). Yet, the variability of the tropical Pacific can explain only part of the rich structure of the monsoon.

Recently, remote teleconnections on East Asia from the North Atlantic region have garnered considerable attention. For example, the Atlantic Multidecadal Oscillation (AMO) has been linked to multidecadal changes in atmospheric circulation and precipitation over China (e.g., Lu et al. 2006; Lin et al. 2016; Wu et al. 2016a, b). The winter Arctic Oscillation (AO) has been shown to influence the EAWM (Wu and Wang 2002) and the occurrence of cold surges over East Asia (Jeong and Ho 2005) by modulating the jet stream and the Siberian High. Gong and Ho (2003) found that a positive AO in late spring can lead to a northward shift of the summertime East Asian jet stream and a redistribution of precipitation over East Asia, while Gong et al. (2011) proposed a spring AO-EASM linkage mediated by western equatorial Pacific SST anomalies and air-sea feedbacks. Additionally, interdecadal variations in the winter $\mathrm{AO}$ have been related to the EASM via anomalous land surface conditions and subsequent modulation of the summer land-sea thermal contrast (Ju et al. 2005).

The North Atlantic Oscillation (NAO) — which is closely related to the $\mathrm{AO}$ - also has important downstream influences on Asian climate, chiefly via quasi-stationary wave propagation of upper-tropospheric anomalies along the Asian jet. This propagation pathway has been highlighted by a number of studies, both in the context of the NAO (e.g. Watanabe 2004; Sung et al. 2006) and more generally in terms of teleconnections with the East Asian region (e.g. Lu et al. 2002; Enomoto et al. 2003). The early studies on this subject have focussed on the (simultaneous) link during the winter season, when the NAO is strongest and most clearly defined in terms of its traditional measures. Interannual variations of the winter NAO were found to be significantly correlated with winter temperature (Wu and Huang 1999; $\mathrm{Li}$ and Wang 2003; Watanabe 2004) and rainfall (Xu et al. 2012; Xiao et al. 2015) anomalies over East Asia. The winter NAO can also have a lagged impact on Eurasian climate by modulating, for example, snow-cover and associated largescale atmospheric circulation in spring and summer (Ogi et al. 2003; Xin et al. 2010) affecting springtime vegetation growth (Li et al. 2015), spring temperature (Yu and Zhou 2004), the timing of the onset of the Meiyu front (Xu et al. 2001), spring droughts (Xin et al. 2006) as well as summertime floods/droughts in parts of China ( $\mathrm{Fu}$ and Zeng 2005), and monsoonal precipitation in eastern Asia (Sung et al. 2006). As such, improving the prediction skill of the winter NAO (e.g., based on antecedent Atlantic SST; Fan et al. 2015; Tian and Fan 2015) is crucial.

However, the NAO is a prominent teleconnection pattern all year round, albeit with a well-defined seasonality (e.g., Portis et al. 2001; Hurrell et al. 2003). Recently, the (lagged) impact of the NAO defined over months/seasons other than the canonical winter has been noted. Gu et al. (2009) found a link between January-March NAO and the main modes of summer precipitation variability over China, while the spring NAO was associated to the following summer's EASM rainfall and circulation via changes in the North Atlantic sea surface temperatures (SSTs). In particular, Wu et al. (2009) showed that the Spring NAO and ENSO can be used as predictors to develop a simple forecast model for EASM strength. A similar SST mechanism was invoked to explain the influence of the summer NAO on September precipitation over China (Xu et al. 2013), although the spring and summer NAO may actually interfere (Zheng et al. 2016). May NAO variations were linked to the frequency of summer extreme precipitation over the Yangzte river (Tian and Fan 2012), and the summer NAO to large-scale temperature, precipitation and circulation anomalies over East Asia (Folland et al. 2009; Linderholm et al. 2011; Sun and Wang 2012), as well as the eastern Tibetan Plateau (Liu and Yin 2001). The NAO may also modulate other teleconnection links; for example, the spring NAO played an important role in the recent strengthening of the EASM-ENSO relationship (Wu et al. 2012).

In addition to the above footprint at the interannual scale, longer-term NAO signals over East Asia have also been identified. For example, the winter NAO has been suggested to affect interdecadal climate variability over China by modulating winter and summer temperature (Sun et al. 2008; Yuan and Sun 2009; Zuo et al. 2016), and spring and summer precipitation (Zhou 2013; Xu et al. 2015), including the occurrence of droughts (Xin et al. 2006); yet, these links are non-stationary (Yuan and Sun 2009). The recent cooling over the eastern edges of the Tibetan Plateau has also been related to long-term variations of the winter NAO (Li et al. 2008).

The literature therefore provides extensive evidence of the NAO's impacts on the EAM across a broad range of timescales. However, our understanding of this link is far from complete. In particular, we identify three knowledge gaps that still need to be addressed.

Firstly, the majority of past investigations has focused on seasonal to decadal time scales, while teleconnections at intraseasonal scales are largely unexplored. An obvious reason is that the NAO variance peaks at the former timescales (Feldstein 2000). However, the dynamical processes associated with the excitation, maintenance, and decay phases of an NAO-event life cycle take place over roughly a $2-3$-week period (e.g., Feldstein 2003; Keeley et al. 2009). Therefore 
analyses based on monthly or seasonal mean data introduce a temporal averaging over several shorter-term NAO events. While this has arguably merits, for example by reducing the noise in the data, it also hinders the understanding of the fundamental dynamics underlying NAO-related teleconnection patterns. For example, Watanabe (2004) showed that convergence anomalies over the Mediterranean precede the wintertime NAO peak, and that downstream propagation occurs during the decay stage of the NAO cycle. Sung et al. (2010) investigated the vertical structure of winter downstream anomalies, distinguishing between upper-tropospheric wave trains common to both NAO positive and negative events and surface pressure anomalies occurring only during the latter. Linderholm (2011) found a propagation of the summer NAO signal to eastern Asia about 1 week after the peak of both positive and negative NAO phases.

Secondly, the NAO is typically defined on a monthly or seasonal basis, using either station data or empirical orthogonal functions (EOFs). Both methodologies assume a stationary spatial pattern during the targeted season. While the impacts during the growing, peak and decay phases of such pattern can be separated (e.g., Linderholm et al. 2011), its spatial evolution is entirely overlooked.

Finally, most individual studies have addressed the NAOEAM link during a specific season, if not single months, as summarized above. While the conclusions drawn by different studies are not necessarily incompatible, the wide range of analysis techniques and NAO definitions makes it difficult to collate them into a unitary picture of the NAO's influence on both the EASM and EAWM.

We further note that not accounting for the rapidly-evolving dynamics driving atmospheric teleconnections poses important challenges in identifying lagged links, and ultimately obscures any application to near-term predictability studies (Nigam and Baxter 2015). This is especially relevant here since the predictability of the EASM, and corresponding droughts or flooding, can be improved by accounting for the NAO influence (e.g., Wu et al. 2009, 2016b).

This paper aims to address the shortfalls outlined above. Specifically, it investigates the observed influence of the NAO's spatio-temporal evolution on the EAM at intraseasonal timescales during both the summer (June to August, JJA) and extended winter (December to March, DJFM) seasons. The NAO is defined as the most recurring temporal series of spatial variability patterns during the relevant season using the extended EOF (EEOF) procedure (Weare and Nasstrom 1982). The rest of the manuscript is organized as follows: Sect. 2 details data and methods used in the analysis. The EEOF-based NAO is described in Sect. 3, showing the additional insights provided by this approach compared to an EOF or station-based analysis. Section 4 documents the statistical links between the EEOF-based NAO and East Asian climate, while a dynamical interpretation of the results follows in Sect. 5. Finally, Sect. 6 provides concluding remarks.

\section{Data and methodology}

The primary datasets used in this paper are the 6-hourly European Centre for Medium-Range Weather Forecasts (ECMWF) Interim Reanalysis (ERA-I; Dee et al. 2011) at $0.7^{\circ} \times 0.7^{\circ}$ horizontal resolution, and the Climate Prediction Center's (CPC) pentad Merged Analysis of Precipitation (CMAP; Xie and Arkin 1996) at $2.5^{\circ} \times 2.5^{\circ}$ resolution. The former is used to characterize near-surface climate (temperature) and the three-dimensional atmospheric circulation, while the latter provides precipitation estimates. Both datasets have a global coverage, thus allowing a geographically comprehensive portrayal of the NAO and its climate footprint. Two daily station-based datasets of temperature and precipitation were also used to provide a regional, high-resolution validation to the larger-scale analysis: the $0.5^{\circ} \times 0.5^{\circ}$ Asian Precipitation-Highly-Resolved Observational Data Integration Towards Evaluation of water resources (APHRODITE) for East Asian precipitation (Yatagai et al. 2012) and temperature (Yasutomi et al. 2011), and the $0.5^{\circ} \times 0.5^{\circ}$ E-OBS for European temperature and precipitation (Haylock et al. 2008). The analysis focuses on the 30 -year period 1979-2008, avoiding discontinuities linked to the beginning of satellite data assimilation in reanalyses in 1979, and is carried out at pentad resolution by averaging the data into consecutive non-overlapping 5-day averages (73 for each year). Anomalies are computed with respect to their 30 -year pentad climatology. ERA-I data were regridded to $2.5^{\circ} \times 2.5^{\circ}$ resolution before the analysis in order to match CMAP resolution and reduce the influence of small-scale spatial features.

The NAO is defined by applying the Extended Empirical Orthogonal Function (EEOF) technique (Weare and Nasstrom 1982) to pentad-mean 500-hPa geopotential height anomalies over the Atlantic sector $\left(20^{\circ}-80^{\circ} \mathrm{N}, 90^{\circ} \mathrm{W}-40^{\circ} \mathrm{E}\right)$. This is preferable to using SLP, which is more directly influenced by local meteorological processes, and allows for a clearer analysis of the NAO's large-scale circulation structure and downstream influences (see, for e.g., Nigam and Baxter 2015). The EEOF-based NAO is denoted as NAOEE hereafter. The EEOF technique extracts the auto-correlated variability within the sub-seasonal cycle and, unlike the more traditional EOF analysis, does not assume spatial stationarity. Additionally, there is no assumption or imposition of any specific periodicity. We describe the spatiotemporal evolution of the NAO as a five-pentad sequence of spatial patterns associated with a single principal component time series (e.g. Baxter and Nigam 2013). The choice of a 5 -member temporal sampling window is consistent with the 

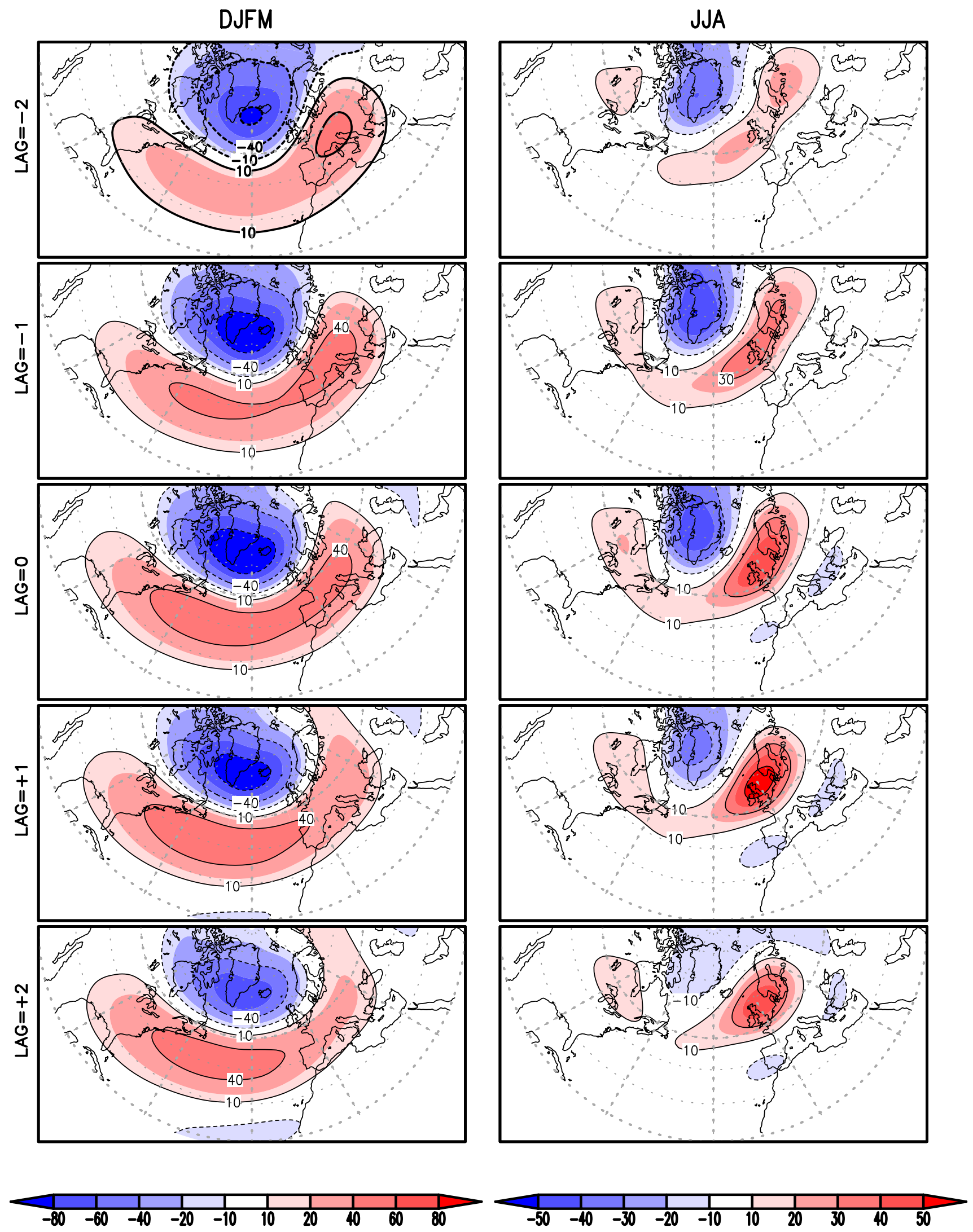

Fig. 1 The first mode of pentad 500-hPa geopotential height variability $(\mathrm{m})$ from EEOF analysis, constituing the NAO pattern. The data covers the period 1979-2008 for (left) DJFM and (right) JJA. Each

lag represents a pentad (5 days) interval, with negative (positive) lags showing the growing (decaying) phase and the lag $=0$ showing simultaneous anomalies 
teleconnection analysis in Nigam and Baxter (2015), and is further discussed in Sect. 3 below. The NAO is therefore not just a single spatial pattern as in a conventional EOF analysis, but rather the most recurrent temporal series of spatial patterns. We analyse both the extended boreal winter (December-March; e.g., Hurrell et al. 2003) and the boreal summer (June-August).

The statistical links between the NAO and East Asian climate are investigated using least-squares linear regressions and correlations. The analysis focuses on the intraseasonal (10-90 days) timescale, isolated by applying a band-pass Lanczos filter to pentad data. This highlights the spatio-temporal evolution of the NAO pattern in relation to its underpinning dynamics and life cycle. The correlation between the filtered and unfiltered first principal components (PC1s) from EEOF analysis are 0.64 and 0.71 for the winter and summer seasons, respectively, indicating that the intraseasonal time scale explains $40-50 \%$ of the total NAO variance.

Given the strong influence exerted by ENSO on both the NAO and the EAM variability (e.g., Wu et al. 2003; Folland et al. 2009), the NAO-EAM teleconnections may be incorrectly attributed if the ENSO-related component is not first isolated and removed from each time series. A widelyused approach to do so, which we adopt here, is to subtract the simultaneous least-square regression of each variable on an indicator of ENSO variability, under the assumption of linearity in the ENSO impact (e.g., Kucharski et al. 2009; Compo and Sardeshmukh 2010). The residual time series, to the first order, will reflect only the ENSO-independent component. Here ENSO is described by the SST anomalies averaged over the Niño3.4 region $\left(5^{\circ} \mathrm{S}-5^{\circ} \mathrm{N}, 170^{\circ}-120^{\circ} \mathrm{W}\right)$. However, it is important to note that all our findings are qualitatively robust to the inclusion of ENSO-related variability. Indeed, the patterns computed when the analysis is repeated without ENSO removal are very close to those derived from the original analysis, which is perhaps not surprising given our emphasis on intraseasonal variability. Additionally, it was verified that repeating the above procedure to remove the impact of the Madden-Julian Oscillation (MJO) did not result in any noticeable changes in the regression patterns discussed below.

To prevent issues related to the large autocorrelation inherent in our time series, the significance of the correlations between the NAO-EE PC1 and other meteorological variables is evaluated using a Monte Carlo approach with 1000 random samples (following, for e.g., McCabe et al. 2004). Both the 90 and $95 \%$ confidence levels are displayed in all relevant figures.

In order to compare and contrast the EEOF-based analysis with other previously-used methods, both an EOF-based and a pseudo-station NAO index were calculated (denoted as NAO-E and NAO-S, respectively). The NAO index is often defined by the difference in sea-level pressure (SLP) between a northern observing station in Iceland and a southern one varying among Ponta Delgada (Azores), Lisbon (Portugal), or Gibraltar. A pseudo station index was derived from the daily ERA-I anomalies using grid points at $\left(65^{\circ} \mathrm{N}\right.$, $\left.23^{\circ} \mathrm{W}\right)$ and $\left(38^{\circ} \mathrm{N}, 9^{\circ} \mathrm{W}\right)$, representative of Stykkisholmur (Iceland) and Lisbon (Portugal), respectively. Following Hurrell (1995), the time series at the two points were then normalized prior to differencing by using the daily standard deviation of the respective anomalies. We note that the selection of the southern station, given the large longitudinal difference among the possible choices, can significantly affect the description of the circulation features associated with the NAO, especially during the summer. Therefore, the station-based index might have deficiencies in capturing the temporal variability of the NAO all-year round given the fixed geographical locations and larger noises from smallscale and transient circulation phenomena (e.g., Li and Wang 2003).

We characterise the strength of the large-scale EASM circulation using the Wang et al. (2001) dynamical index, based on the latitudinal difference of the 850-hPa zonal wind between a southern $\left(5^{\circ}-15^{\circ} \mathrm{N}, 100^{\circ}-130^{\circ} \mathrm{E}\right)$ and northern $\left(20^{\circ}-30^{\circ} \mathrm{N}, 110^{\circ}-140^{\circ} \mathrm{E}\right)$ region (see the boxes in Fig. 5).

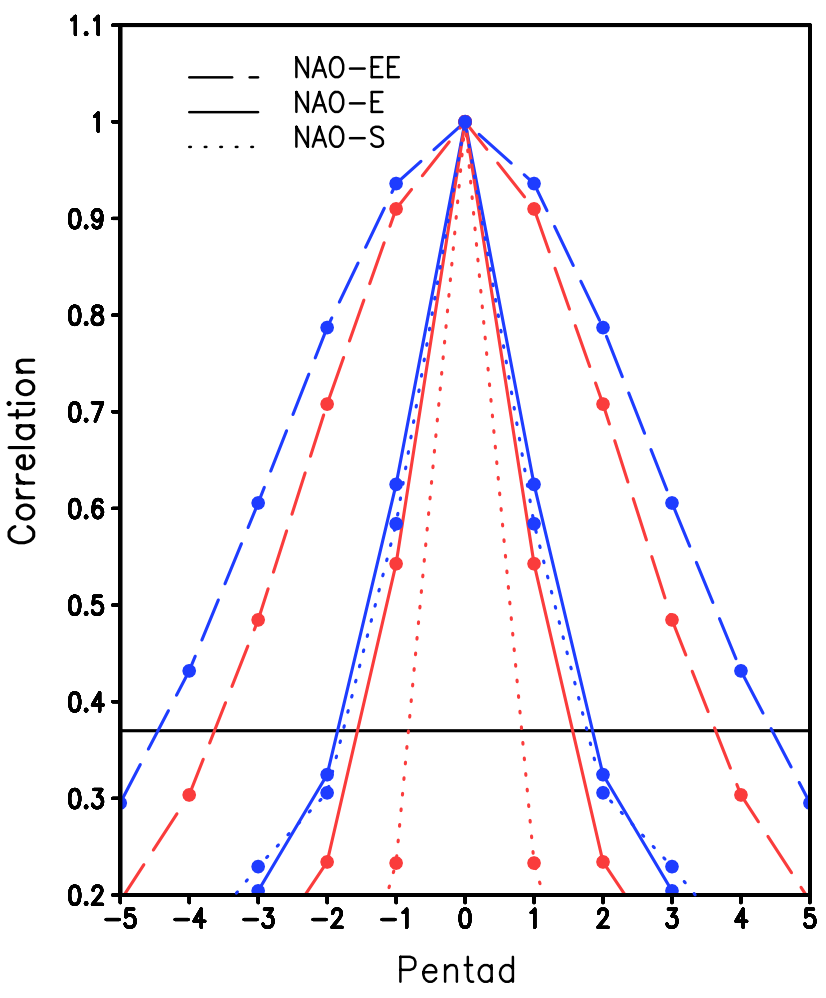

Fig. 2 Autocorrelations of the pentad NAO indices (the PC1 from EEOF analysis, denoted as NAO-EE; the PC1 from traditional EOF analysis, denoted as NAO-E; the pseudo-station NAO, denoted as NAO-S) for DJFM (blue) and JJA (red). The horizontal black line marks the $\mathrm{e}^{-1}$ value 

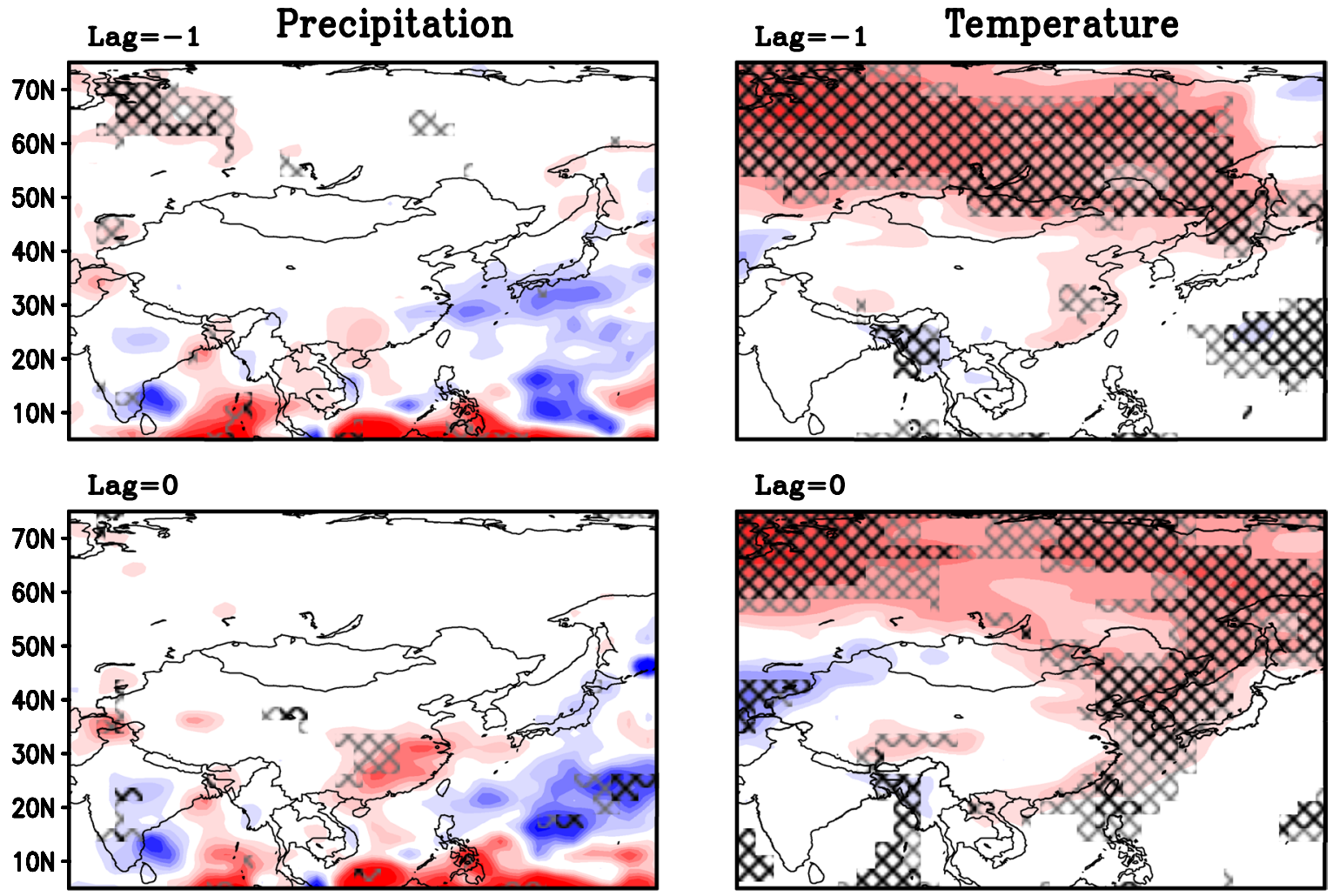

\section{Lag $=+1$}

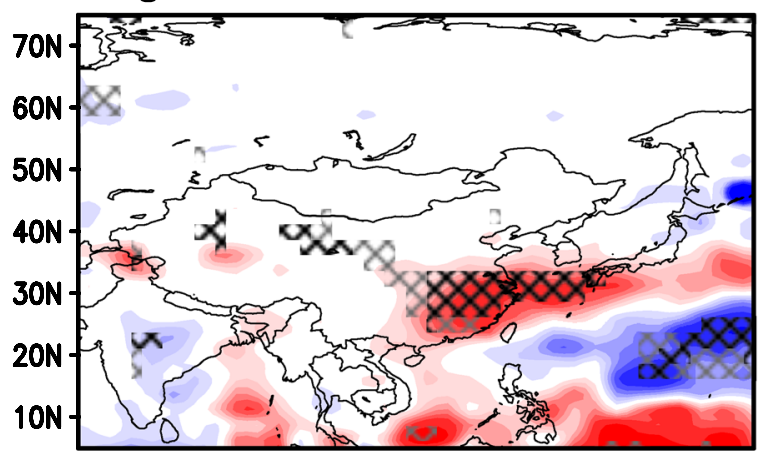

$\mathrm{Lag}=+1$

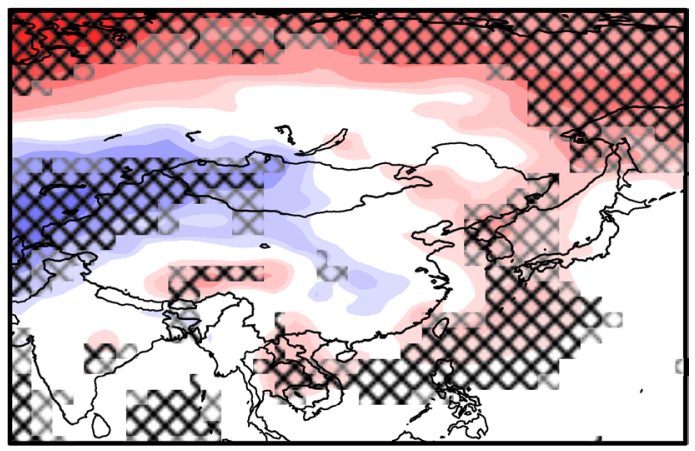

$\mathrm{Lag}=+2$

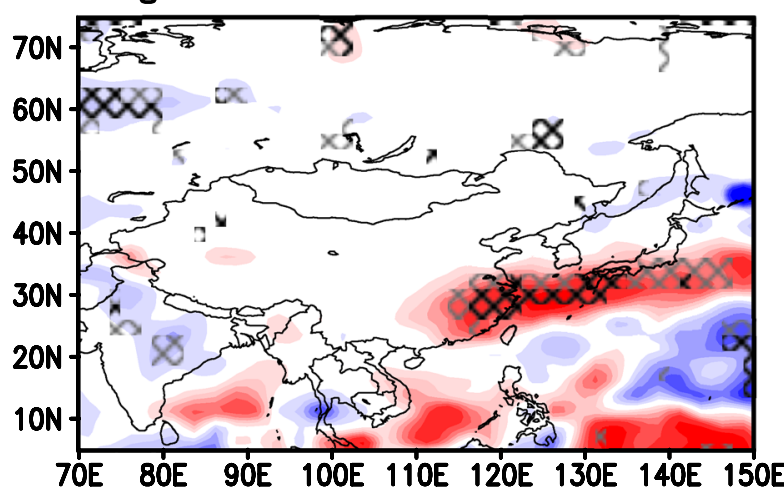

$\mathrm{Lag}=+2$
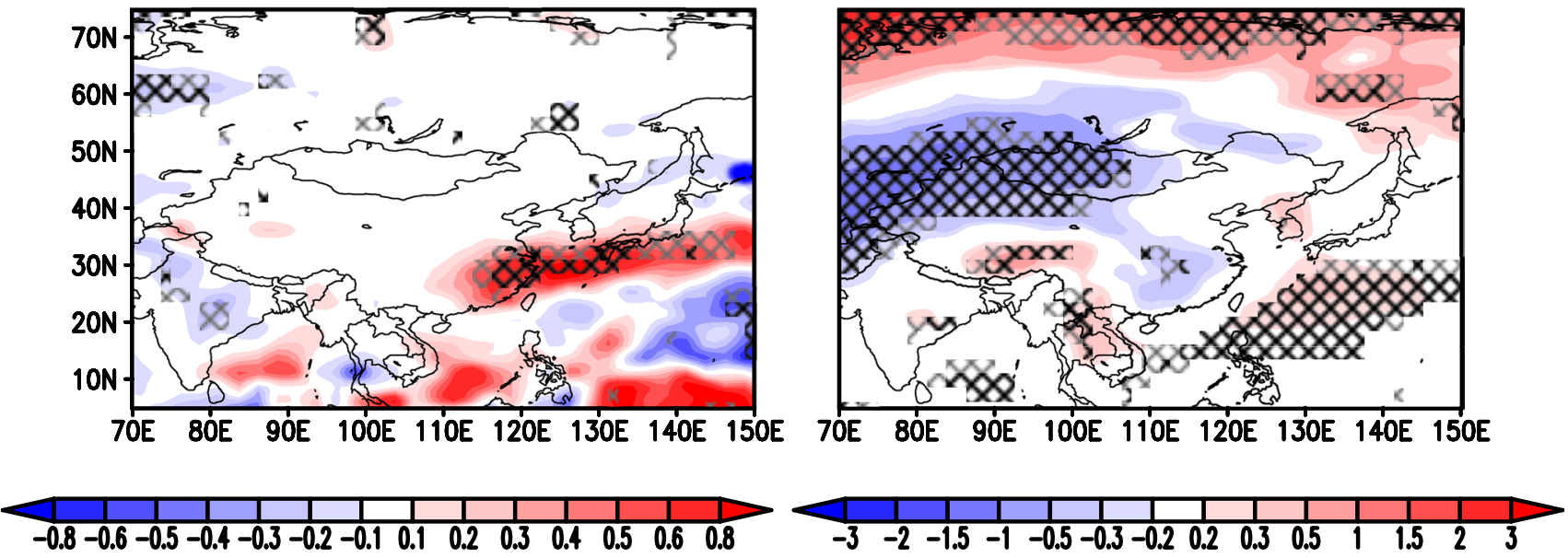
4Fig. 3 Lead-lag regressions (shades) of pentad (left) precipitation $\left(\mathrm{mm} \mathrm{day}^{-1}\right)$ and (right) 2 -m temperature $\left({ }^{\circ} \mathrm{C}\right)$ on the NAO-EE PC1 during DJFM from $t=-5$ days (lag $=-1$ ) to $t=+10$ days $(\operatorname{lag}=+2)$. The effect of El Niño was removed and the data were filtered to retain intraseasonal variability (10-90 days) before computing the patterns. The cross-hatching marks regions where the correlation exceeds the $90 \%$ (grey) and 95\% (black) confidence levels, estimated by using a Monte Carlo approach

This low-level westerly shear index reflects not only the strength of the tropical westerlies but also the intensity of low-level vorticity associated with monsoon boundary-layer moisture convergence. From a circulation perspective, it captures variations in both the Western North Pacific monsoon trough and the Subtropical High, two key features associated with the EASM (Wang and Fan 1999).

Finally, the downstream impact of the NAO via uppertropospheric dynamics is illustrated by using the horizontal component of the Takaya and Nakamura (2001) wave activity flux, a generalisation of the Plumb (1985) flux.

\section{A spatially varying North Atlantic Oscillation pattern}

The leading mode of the most recurrent five-pentad sequences of (unfiltered) $500-\mathrm{hPa}$ height anomaly patterns from EEOF analysis are displayed in Fig. 1. During the boreal winter, the mode features the traditional NAO dipole pattern over the North Atlantic (shown in its positive phase in Fig. 1, left column). The mode is centred on the peak phase of the NAO as its maximum amplitude occurs at lag $=0$ and the growing and decaying phases are approximately symmetric around lag $=0$. Interestingly, while the Icelandic low pulses but remains stationary in space, the core of the high pressure region exhibits a noticeable westward shift through the sequence, from continental/ southern Europe to the western North Atlantic. The NAO also emerges as the leading mode of variability during the boreal summer, and is shown in its positive phase in the right column of Fig. 1. The pattern, weaker and of smaller spatial extent than its winter counterpart, is characterised by a northwestern extension of the Azores high and an eastwardshifted Icelandic low, in agreement with previous studies (Folland et al. 2009). The modal evolution again shows a pulsing but quasi-stationary low, while the high undergoes a zonal expansion and subsequent contraction. It is noteworthy that positive and negative centres do not vary in phase: the former reaches maximum magnitude at lag $=+1$, while the latter peaks during the development phase $($ lag $=-1)$. This is a potentially important yet overlooked dynamical feature of the summer NAO pattern at intraseasonal time scales. These two leading modes explain 11.7 and $7.2 \%$ of the 500-hPa geopotential height total variance during winter and summer, respectively, consistently with other analyses (e.g., Baxter and Nigam 2013) based on the 200-hPa geopotential height). These values are small compared to those obtained from traditional EOF analysis (21.4 and 14.8\%, respectively) but are the norm for EEOFs since the use of a series of five spatial patterns as opposed to a single pattern in the covariance matrix increases the overall variance.

The corresponding patterns for the NAO-E, obtained from lead/lag regressions on the EOF principal component, are shown in the supplementary Fig. S1. A comparison of Fig. 1 and S1 helps to illustrate the key advantage of the EEOF approach over the traditional EOF. While both methods yield very similar spatial patterns for the mature phase (i.e., lag =0), the temporal evolution portrayed by the EOF analysis is subdued, especially in the summer, as shown by the weaker regressions at both positive and negative lags. A further comparison with the NAO-S index confirms that during both seasons the NAO-EE retains a close link to the original interpretation of the NAO as a sea-level pressure dipole (Fig. S2). The temporal variability of the NAO-EE time series (PC1) is related to those of the other two indices, with correlations of approximately 0.8 in winter and slightly lower values in summer. The EEOF NAO therefore captures in full the information provided by the canonical NAO definition, while providing additional insights through a timevarying spatial pattern and an enhanced ability to portray the details of the oscillation's life-cycle. Indeed, the EEOF PC1 exhibits a much longer temporal autocorrelation than the two alternative NAO indices considered here (Fig. 2). The NAO-E and NAO-S indices display small autocorrelation beyond lags of \pm 1 pentad for both winter and summer, indicating the predominance of high-frequency (synoptic) variability. The $\mathrm{e}^{-1}$ threshold suggests an $\sim 3-4$ pentad duration of winter NAO events in the EOF portrayal, consistent with life-cycle estimates in the literature (e.g. Feldstein 2003; Keeley et al. 2009). The EEOF PC1, on the other hand, shows a meaningful autocorrelation beyond three pentads during both the summer and winter seasons, consistently with the EEOF emphasis on pattern development and decay as it intrinsically appears in the data, and contrasts with its shorter-lived statistical approximation via lead-lag correlations/regressions. This is particularly valuable in the context of subseasonal variability, allowing the EEOF regressions to capture the time-varying footprint and teleconnections associated with the evolution of the NAO, with potential broader implications for identifying and understanding novel sources of sub-monthly predictability.

The EEOF analysis described above comprises variability across all frequencies to ease the comparison of the NAOEE with other diagnostics. However, as this study aims to emphasize NAO teleconnections at subseasonal time-scales, the contribution of the lower frequency variability needs to be removed. The evolution of the sub-seasonal NAO spatial 

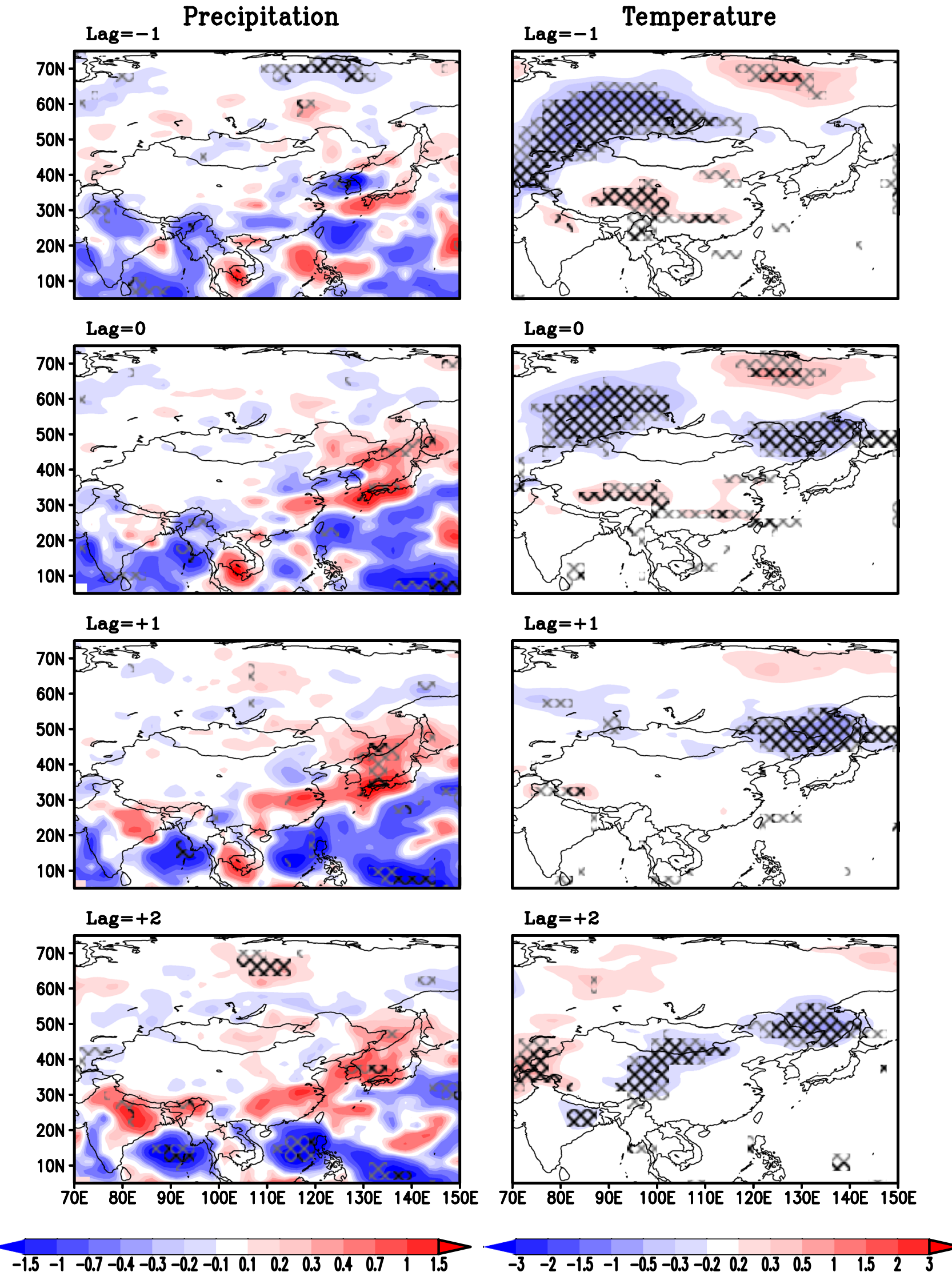

Fig. 4 As Fig. 3, but for JJA 
pattern, computed by regressing the pentad 500 -hPa geopotential anomalies on the 10-90 day filtered PC1 associated with the EEOF-based NAO, is displayed in Figure S3, while an estimate of the NAO time-scale is provided by the autocorrelation shown in Fig. S4. The pre- to post-mature phase (lags $=-1$ to +1$)$ patterns bear considerable resemblance to those of the total (unfiltered) NAO: for example, the westward shift of the core of the NAO's positive pole during the winter, as well as its expansion and successive contraction during the summer, are apparent in Fig. S3. However, removing the low-frequency variability has a substantial impact on the duration of NAO events: the autocorrelation falls below the $\mathrm{e}^{-1}$ folding scale after less than 10 days, suggesting a strong influence of interannual and longer time-scales on the persistence of the NAO anomalies and their slow decay beyond two pentads (e.g., Barnes and Hartmann 2010). Furthermore, the impact of removing the low-frequency variability is larger on the winter than the summer NAO, resulting in almost identical decorrelation times at subseasonal time scales (e.g., Keeley et al. 2009). This further suggests the presence of common dynamical processes underlying the winter and summertime NAO evolution at intraseasonal time scales. Finally, we note that this shorter decorrelation time is still consistent with our choice to describe the NAO as a series of 5 pentads.

A number of factors, both internal and external to the NAO's subseasonal dynamics, may contribute to extend the NAO's persistence at relatively low frequencies (e.g., Franzke and Woollings 2011). However, a detailed investigation of this aspect is beyond the scope of this study.

An additional point that merits discussing is the choice of the timescale adopted in the present analysis. For a stationary EOF pattern, intraseasonal timescales capture the single NAO events, while on longer scales the dominant NAO mode for the different seasons or years emerges. For EEOFs, intraseasonal timescales will highlight the non-stationary nature of the pattern and of the associated teleconnections, while the longer timescales will naturally overshadow the life-cycle of individual NAO episodes. This justifies our choice of focussing on periods of 10-90 days.

\section{Teleconnections with the winter and summer East Asian climate}

The impact of the intraseasonal EEOF NAO pattern on Asian climate is illustrated in terms of regressions of precipitation, temperature and SLP on the NAO-EE (filtered and with ENSO removed) ${ }^{1}$ PC1 for winter (Figs. 3, 5 left

\footnotetext{
1 We note that ENSO removal results in only very minor changes to the NAO patterns displayed in Fig. 1 and S3.
}

column) and summer (Figs. 4, 5 right column). The patterns are displayed at lags of $-1,0,+1$ and +2 pentads. Accounting for the fact that we do not expect the teleconnection across Eurasia to be simultaneous, these lags correspond to the growth, mature and initial decay phases of the NAO (cfr. Sect. 3). This allows to track the development of the downstream imprint of the NAO signal and the expected lagged response over Asia. We opt not to show lag +3 pentads, thus partially losing the footprint of the final decay phase of the NAO, because we do not want to blur the dynamical interpretation of our results by mixing different life-cycles.

The most remarkable feature of the winter precipitation pattern is the development of a band of excess precipitation extending zonally between south-eastern China and the western Pacific and reaching the southernmost part of Japan (Fig. 3 left column). Initially located along the Equator, the rain-band gradually moves northeastward while growing in magnitude and spatial extent as the NAO evolves, and finally peaks at lag +2 . This pattern is very different from the results found using a seasonal EOF-based NAO/AO index (e.g., Liu and Yin 2001), consistently with the different mechanisms that may be at play on longer times-scales. As the EAWM is characterised by cold, dry lower-tropospheric northeasterlies and low precipitation rates across China (maximum of $3 \mathrm{~mm} \mathrm{day}^{-1}$ over the southeastern regions), regression values approaching $1 \mathrm{~mm} \mathrm{day}^{-1}$ suggest that the NAO plays a major role in modulating the cold-season precipitation (up to $30 \%$ of the climatological DJFM precipitation over eastern China; see Fig. S6).

Near-surface temperature also exhibits a prominent evolution (Fig. 3 right column). The initial extensive positive anomaly across northern Eurasia highlights the large footprint of the growing phase of the NAO, and is largely consistent with the previous EOF-based NAO/AO analyses (e.g., Hurrell 1996; Gong et al. 2001). At later lags, the warm anomaly gradually weakens and shifts northward, while an area of colder anomalies moves eastwards across central Asia and Mongolia, and eventually spreads over a large part of the region $(\mathrm{lag}=+2)$.

Figure 4 shows the same results as Fig. 3 but for the boreal summer season (JJA). As for winter, precipitation and temperature show a remarkable evolution during the NAO cycle. The precipitation regression displays two zonally-elongated bands forming a meridional dipole across the region, characterized by drier conditions from southern India to the north-equatorial Pacific and wetter anomalies over the land areas to the north/northeast. Albeit only locally significant, both anomalies peak in magnitude at lag $=+2$.

The temperature evolution is characterised by a strong modulation of the amplitude of the anomalies while the main centres of action remain approximately stationary in space. The initial cold and widespread anomaly over western and central Russia decreases to a negligible amplitude by 


4Fig. 5 Lead-lag regressions of pentad sea-level pressure (hPa, shades) and 850 -hPa winds $\left(\mathrm{ms}^{-1}\right.$, black arrows) on the NAO-EE PC1 for (left) DJFM and (right) JJA from $\mathrm{t}=-5$ days $($ lag $=-1)$ to $\mathrm{t}=+10$ days $(\mathrm{lag}=+2)$. The effect of El Niño was removed and the data were filtered to retain ntraseasonal variability before computing the patterns. Hatching mark regions where the correlation exceeds the $90 \%$ (grey) and 95\% (black) confidence levels, estimated by using a Monte Carlo approach. The boxes mark the regions $\left(5^{\circ}-15^{\circ} \mathrm{N}, 100^{\circ}-130^{\circ} \mathrm{E}\right)$ and $\left(20^{\circ}-30^{\circ} \mathrm{N}, 110^{\circ}-140^{\circ} \mathrm{E}\right)$ used to compute the EASM index

lag $=+1$, and is replaced by a weaker warm anomaly one pentad later. Simultaneously, the initial small positive temperature anomaly over eastern China turns to large negative values at lag $=0$, and successively extends southwestward. These features are indicative of an eastward-propagating negative temperature signal across the domain.

Inspection of the sea-level pressure and low-level wind patterns provides a consistent dynamical context for the development of the precipitation and temperature signals (Fig. 5). During the winter (left column), as the NAO evolves a positive sea-level pressure anomaly propagates northeastward across Eurasia, replacing the widespread negative anomaly seen in the growth phase (lags $=-1$ and 0 ). This evolution corresponds to a progressive strengthening of the Siberian high, peaking at lag $=+2$. The 850 -hPa circulation evolves accordingly: the initial southwesterlies over the Eurasian mid- and high-latitudes are gradually replaced by northeasterlies, which extend eastward and intensify, leading to the advection of cold air masses over northern China and Mongolia. In the meanwhile, the negative SLP anomalies progressively shift south-eastward over Southeast Asia, where a strong cyclonic circulation develops. This leads to an increased southwesterly moisture transport across the region, where excess precipitation is indeed found. Neither of these features were fully appreciated in previous EOFbased analyses, which only highlighted the negative pressure anomalies across northern Eurasia (e.g., Wu and Wang 2002, looking at seasonal-mean values).

During the summer, the SLP anomalies at lags $=-1$ and 0 feature a zonal dipole across northern Eurasia, consisting of a large anticyclone over western Russia and a weaker cyclone over north-eastern China and the China Sea. As a result, northerlies bring colder air over central Eurasia, while the southwesterly EASM flow is diverted zonally, confining precipitation to Southeast Asia. At later lags, the anticyclone weakens and eventually disappears altogether. Negative pressure anomalies appear over northern Russia at lag $=+1$ and grow at lag $=+2$. At the same time, an anticyclonic anomaly forms over China and the western Pacific, peaking at lag $=+2$. This pattern brings warm low-level southwesterlies over central Asia and strengthens the climatological monsoon flow over China, shifting the precipitation northward. In particular, the precipitation anomalies seen at positive lags (Fig. 4) can be related to the positive regressed pressure values to the south-west of the climatological location of the Western Pacific subtropical high, as further discussed in Sect. 5. Both these patterns highlight a remarkable evolution of the regressions in parallel with the growth and decay of the EEOF $\mathrm{NAO}^{2}$.

To ascertain the robustness of the NAO-related surface climate imprint over East Asia, the analysis was repeated using the APHRODITE dataset (Figs. S5, S7). Although geographically bounded and thus potentially less suitable to pinpoint the continental-scale/oceanic nature of the anomalies, APHRODITE is based on station observations and thus represents the "ground truth" against which to corroborate the findings shown in Figs. 3 and 4. A comparison of the latter with Figs. S5 and S7 immediately reveals a close resemblance in terms of magnitude and temporal evolution of the anomalies and location of the areas with the highest statistical significance.

\section{Discussion and dynamical interpretation}

The analysis in Sect. 4 has highlighted consistent anomalous patterns in near-surface climate (temperature and precipitation) and large-scale lower-tropospheric dynamics (sea-level pressure and 850-hPa winds) over the Asian region, with notable changes during the various phases of the NAO's life-cycle. This picture is very different from past analyses, which mainly focussed on quasi-stationary features (e.g., compare the positive pole in SLP over northwestern China in Fig. 8 from Linderholm et al. (2011) with the right-hand column of Fig. 5 here).

Previous studies have interpreted the downstream influence of both the summer and winter NAO in terms of quasistationary upper-tropospheric wave trains emanating from the NAO region and travelling across Eurasia. The different phases of the NAO correspond to significant circulation anomalies and locally to upper-level convergence and vorticity anomalies which can act as a source of wave activity. Some studies have further proposed that the Asian jet stream can facilitate the downstream propagation of the NAO signal by acting as a Rossby waveguide (e.g., Branstator 2002; Watanabe 2004; Linderholm et al. 2011). Additionally, a distinct high-latitude pathway has also been identified, whereby the NAO wave train propagates poleward and then eastward across the northern Eurasian land mass (Li et al. 2008; Sung

\footnotetext{
$\overline{2}$ Interestingly, summer precipitation, temperature and sea-level pressure anomalies associated with the post-mature phase of the NAO and the eastward propagation of its signal across East Asia bear a notable resemblance to the corresponding anomalies associated with the negative phase of the Pacific-Japan pattern (e.g., Kubota et al. 2016). This is intruguing, as it suggests a possible projection of the NAO imprint on this variability mode.
} 


\section{DJFM}
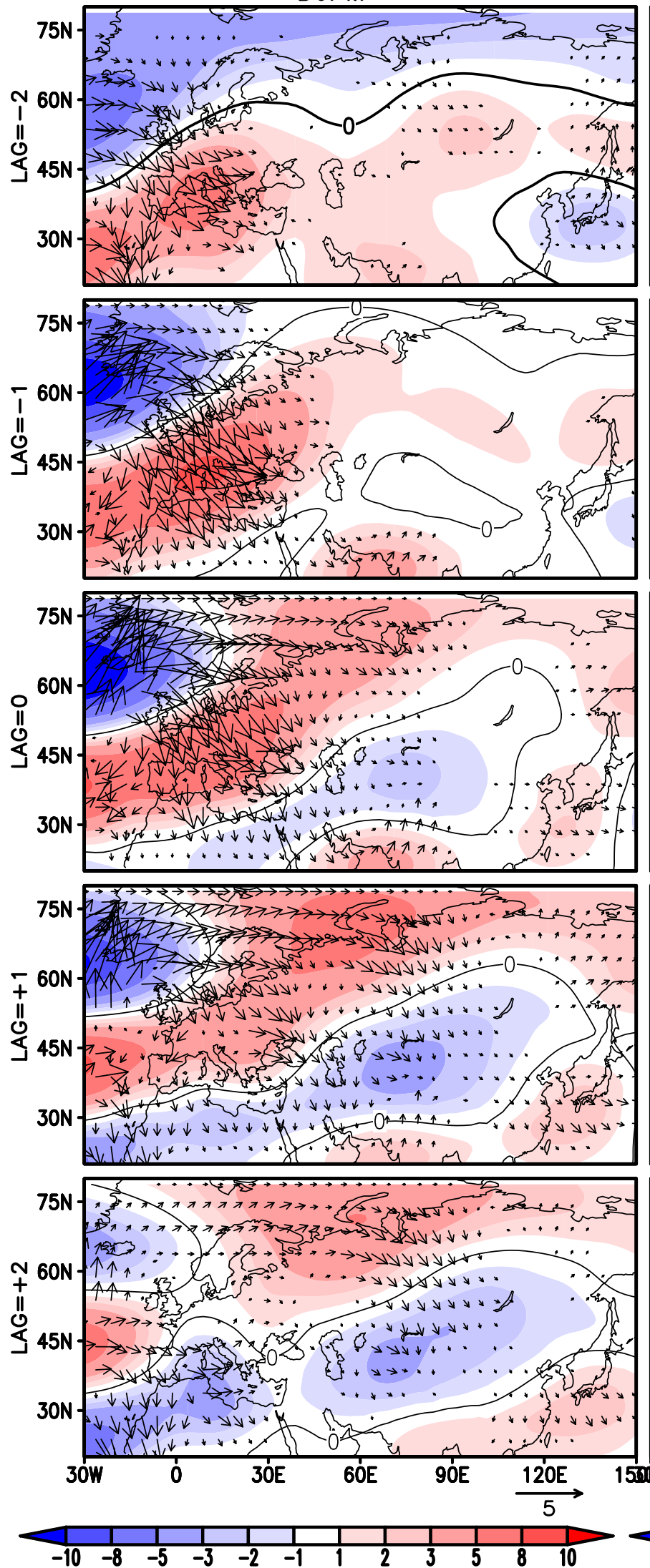

JJA
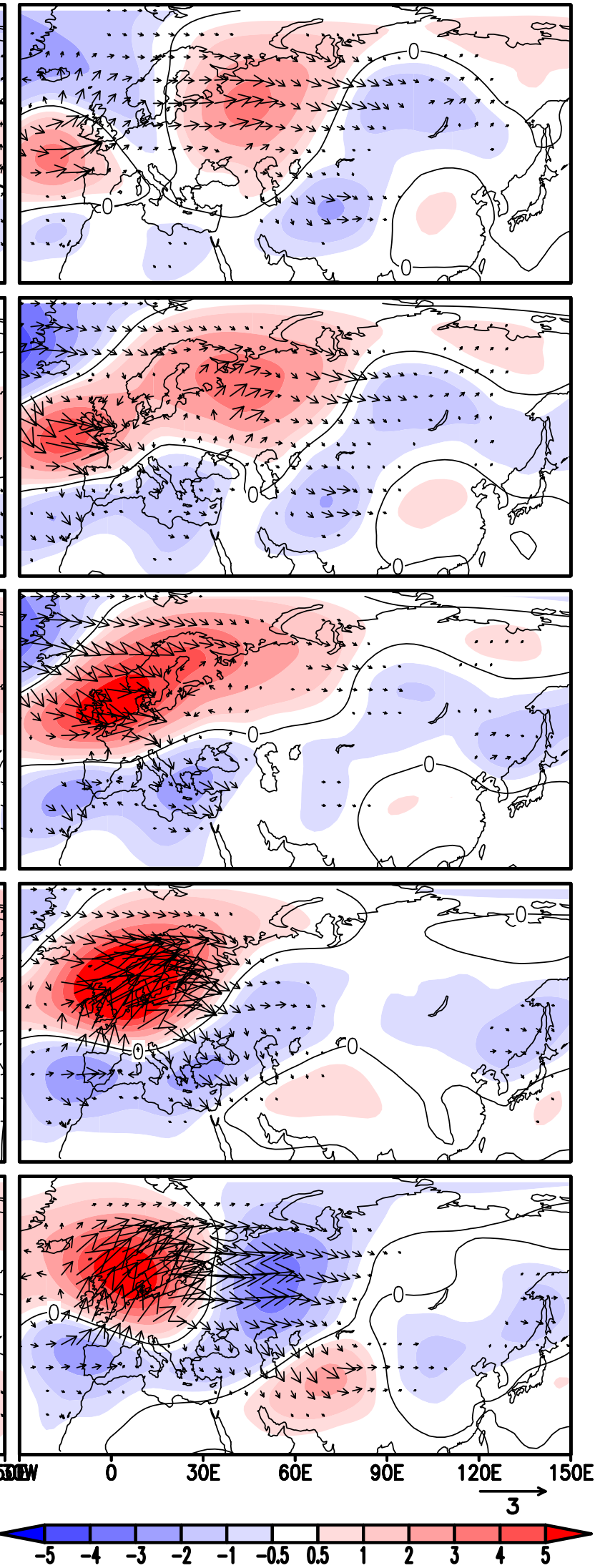
4Fig. 6 Lead-lag regressions of pentad 300-hPa streamfunction $\left(\times 10^{5}\right.$ $\mathrm{m}^{2} \mathrm{~s}^{-1}$, shades) on the NAO-EE PC1 for (left) DJFM and (right) JJA from $\mathrm{t}=-10$ days $(\operatorname{lag}=-2)$ to $\mathrm{t}=+10$ days $(\operatorname{lag}=+2)$. The black lines mark the zero contour. Also shown is the wave activity flux $\left(\times 10^{3} \mathrm{~m}^{2} \mathrm{~s}^{-2}\right.$, arrows $)$ associated with the $300-\mathrm{hPa}$ geopotential height anomalies obtained by regression on the NAO-EE PC1. The effect of El Niño was removed and the data were filtered at intraseasonal scale before computing the patterns

et al. 2010; Song et al. 2014). The prevalence of either pathway has been related to the phase of the NAO (Sung et al. 2011), its seasonal mean anomaly (Linderholm et al. 2011), as well as to preconditioning large-scale conditions, such as El-Niño (Song et al. 2014).

To probe the existence of this mechanism in the context of the present EEOF analysis, we focus on the wave activity at different lags. Figure 6 displays the horizontal wave activity flux corresponding to the $300-\mathrm{hPa}$ geopotential anomalies associated with NAO-EE PC1, together with the anomalous $300-\mathrm{hPa}$ streamfunction. The wave activity flux is a quantity parallel to the wave group velocity, thus indicating the propagation of wave activity. We calculate it following Takaya and Nakamura (2001), ignoring the vertical terms and assuming that the phase propagation term is small enough to be neglected. Divergence (convergence) of the wave activity flux then indicates a source (sink) of stationary wave activity. The streamfunction, rather than the geopotential, is more suitable to represent and analyse upper-level circulation anomalies which extend to low latitudes, as is the case here. The anomaly patterns are now shown from lag $=-2$ to depict the entire evolution and propagation of the upper-tropospheric circulation signals starting from the NAO centres over the North Atlantic.

During the winter season (Fig. 6, left column), the NAO build-up phase (lag $=-2$ ) features a strong wave flux emanating from the NAO negative centre over the North Atlantic and directed south-eastward across Europe. A secondary divergence centre for the wave flux is evident over the central Mediterranean region. As the NAO evolves, the flux intensifies and crosses the Middle East to reach India at the NAO peak $(\mathrm{lag}=0)$. In the post-mature phase, as the NAO northern pole weakens and the southern pole shifts westward (Fig. 1), the wave activity flux also decays $(\operatorname{lag}=+2)$. Interestingly, in addition to the south-eastward branch, a highlatitude pathway also emanating from the North Atlantic region emerges at the NAO peak phase $(\mathrm{lag}=0)$ : this wave flux points eastward across Siberia and turns progressively south-eastward over central Asia while intensifying as the NAO subdues.

Changes in the wave activity flux are accompanied, not surprisingly, by corresponding anomalies in the stream function and meridional wind (Fig. 7). The latter allow to better appreciate regional circulation features associated with the zonally asymmetric component of the teleconnection patterns, but may not be fully revealed in a wind-speed composite due to the pronounced zonal structure of stream function anomalies. A south-eastwards propagating wavetrain, featuring a weak cyclone over the Middle East and anticyclonic circulation over the Indian sub-continent and the eastern part of the Arabian Peninsula, appears during the NAO pre-mature phase (lag $=-1)$, peaks at lag $=0$, and then gradually decays. The northern branch of the wave flux instigates an eastward wave train across Eurasia from Scandinavia to Southeast Asia. This is characterized by an extensive cyclone over central Asia and an anticyclone over southern East Asia, achieving peak amplitude during the NAO post-mature phase. A very similar pattern is seen at $500 \mathrm{hPa}$ (not shown), pointing to a coherent westerly wave propagation across the middle and upper troposphere. The out-of-phase relationship between the southern and northern wave trains generates an overall eastward propagation of the upper-level anticyclonic circulation anomalies across the midlatitudes; at the surface, this evolution results in the eastward propagation of positive SLP regression values across northern Eurasia (Fig. 5, left column).

The wave activity flux and streamfunction anomalies are consistent with a meandering of the westerly East Asian jet stream (EAJS) over East Asia, which results in a progressive intensification and poleward shift of the jet core from its climatological location south of Japan (Fig. 8; see also Zhang et al. 2006). A stronger EAJS is typically associated, on a seasonal basis, with colder winter surface temperatures over eastern Asia, especially over Mongolia and along the eastern coast, and a meridional precipitation dipole featuring drier conditions over eastern China, Japan, and Korea and stronger precipitation over the Maritime continent (e.g., Yang et al. 2002). As the NAO evolves, changes in the position and intensity of the jet core affect the cross-jet circulation: the ascending branch of the upstream direct meridional circulation shifts northward, offsetting the existing subsiding circulation and generating a prevailing southerly flow and a positive precipitation anomaly over eastern China. At the same time, the descending branch moves toward central Asia, and so does the returning northerly cold flow (Fig. 3, left column). The gradual strengthening and shifting of the EAJS is therefore consistent with the weakening and disappearance of the positive temperature anomalies over the East Asian coastline at positive lags. At the same time, we note that an intensified EAJS has previously been associated with decreased precipitation across central and northern China, Korea and Japan, driven by an anomalous low-level dry northerly flow (Yang et al. 2002).

During the boreal summer season the wave activity flux exhibits, as for the winter, two preferred propagation pathways across the Eurasian continent which evolve asymmetrically with respect to the NAO cycle and opposite in phase with each other (Fig. 6, right column). The two 

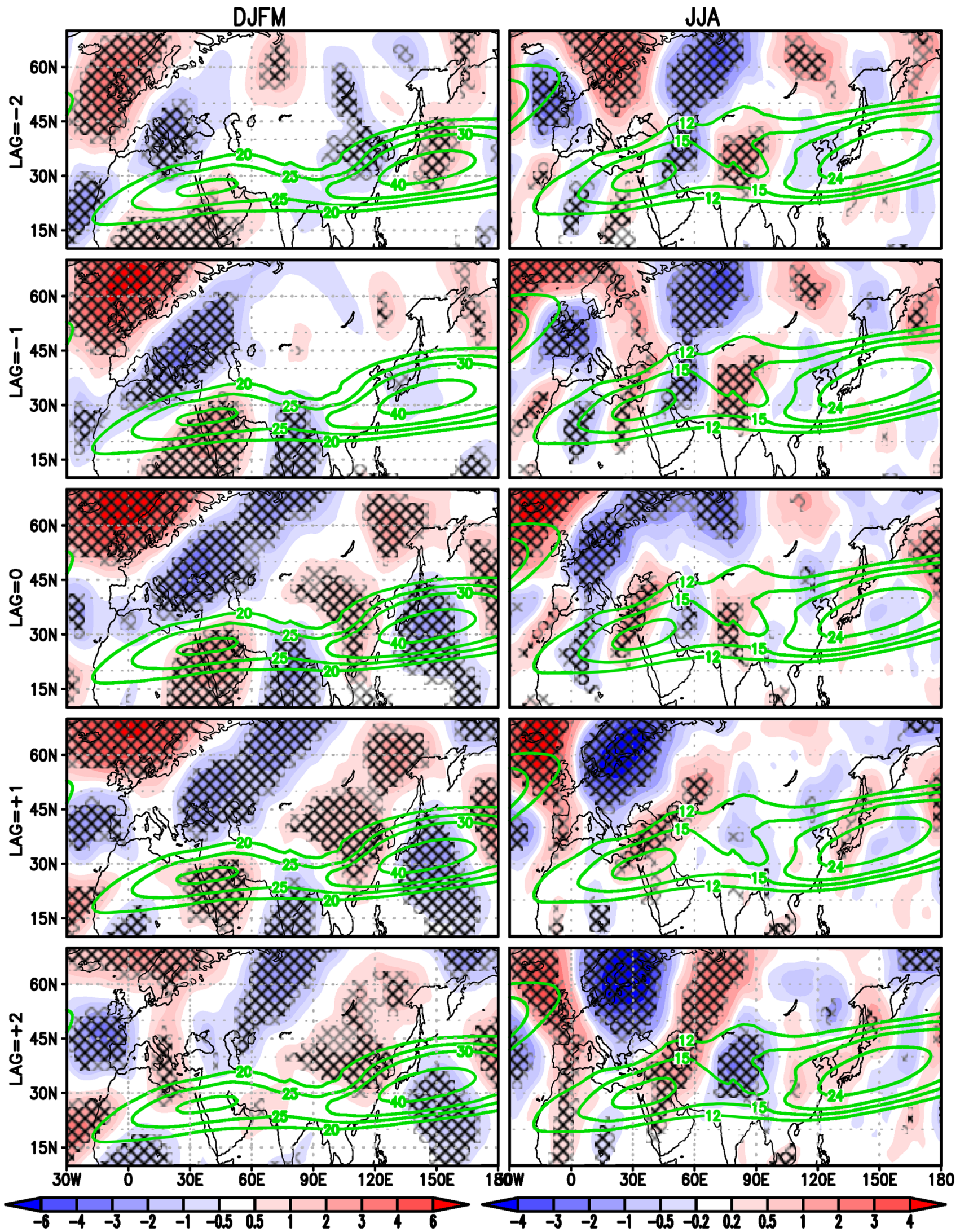
4Fig. 7 Lead-lag regressions of pentad 300-hPa meridional wind (m $\mathrm{s}^{-1}$ ) on the NAO-EE PC1 for (left) DJFM and (right) JJA from $\mathrm{t}=$ -10 days $(\operatorname{lag}=-2)$ to $t=+10$ days $(\operatorname{lag}=+2)$. The green countours represent the 1979-2008 climatological 300-hPa zonal wind (m $\mathrm{s}^{-1}$ ). The effect of El Niño was removed and the data were filtered at intraseasonal scale before computing the patterns. The cross-hatching marks regions where the correlation exceeds the $90 \%$ (grey) and $95 \%$ (black) confidence levels, estimated by using a Monte Carlo approach

branches originate from a single wave flux associated with the NAO's positive pole: as the latter gradually migrates north-eastward and strengthens, so does the former, resulting in a stronger wave flux over the North Atlantic. The flux splits over Eastern Europe, generating a northern zonal branch over Russia, and a south-eastern branch across the Caspian Sea and the Middle East. While both branches are recognizable throughout the NAO cycle, the former retreats westward while the latter extends south-eastwards toward China. Streamfunction anomalies clearly show the downstream propagation of the NAO signal along the wave flux pathways. As the NAO builds up (lag $=-2$ ), a wave train originates from the upper-tropospheric anticyclonic anomaly located northwest of the Iberian Peninsula. This splits, with the southern pathway resulting in an upper-level trough over Pakistan and a ridge over eastern China. At the same time, the northern pathway is associated with a cyclone over eastern Siberia. As the NAO evolves (Fig. 1), the northern SLP pole weakens almost to disappearance, while the southern pole (and its upper-level counterpart displayed in Fig. 6) is more persistent (Fig. 1). Correspondingly, the northern wave train weakens, while the southern pathways now results in an anticyclonic anomaly over western China. The lag $= \pm 2$ patterns are strikingly similar and of opposite sign, a direct consequence of the changes in the driving NAO pattern and, as pointed out earlier, suggestive of an eastward propagation of a quasi-stationary wave. This difference maps very clearly to the regressed upper-level zonal wind (Fig. 8), which displays opposite signs between lag $=-2$ and lag $=+2$ over the subtropical jet region. The area of positive zonal wind anomalies over East Asia roughly matches the location of the southern pole of the Lau et al. (2000) monsoon index, ${ }^{3}$

\footnotetext{
3 The East Asian monsoon index discussed in Lau et al. (2000) is a measure of the 200-hPa meridional shear of the zonal wind across East Asia and essentially captures variations in the upper level circulation associated to changes in precipitation over Indochina and the Western Pacific, the core rainfall area. The relationship between East Asian precipitation and three-dimensional circulation anomalies can be interpreted as a Rossby wave response to anomalous convective heating and associated large-scale vorticity balance (i.e., the Sverdrup balance), which results in an anomalous upper (lower)-tropospheric anticyclone (cyclone) coincident with and northwest of the heating anomaly, and subsidence over eastern China between $25^{\circ}-30^{\circ} \mathrm{N}$. This $850-\mathrm{hPa}$ wind anomalies bear a striking resemblance to those associated with the Wang et al. (2001) EASM index, indicating a close link between the two indices and, ultimately, a common underlying mechanism.
}

where a weaker upper-level jet is associated with weaker monsoonal precipitation over the Yangtze River basin and Japan. Consistently with this, we find a band of positive regressed precipitation over the same region [cf. Fig. 5 here with Fig. 7a in Lau et al. (2000)].

The boreal summer precipitation pattern can also be related to the Wang et al. (2001) EASM index discussed in Sect. 2. A higher index value corresponds to rainfall increases along a zonal band extending from the South China Sea across the Philippines and into the Central Pacific, with a concomitant decrease along the Meiyu/Baiu band, spanning the Yangtze river basin, the East China Sea and Japan. Referring back to Fig. 5, as the NAO evolves from negative to positive lags, we see a sharp decrease in the monsoon index (see Table 1) associated with positive zonal anomalies over southeastern China (the northern box of the index) and an area of intense easterly anomalies over the north equatorial western Pacific (the southern box). This meridional anomalous dipole is consistent with the positive values of regressed SLP over the region which lead to an anticyclonic circulation anomaly - in other words, a southwestward extension of the climatological Western Pacific Subtropical High - at positive lags (Fig. 5). Coherently with the above interpretation, the sharp decrease in monsoon index with progressing lags is associated with a band of positive precipitation values along the monsoonal front and a region of negative values to the southeast.

Finally, it is worth noting that, while our analysis has primarily focused on East Asia, NAO-related anomalies in precipitation and temperature are also present over South Asia (Figs. 3, 4). This link has received comparatively little attention so far, and the underlying dynamical mechanisms are debated. Among the few existing studies, statistically significant inverse interannual correlations were identified between the previous winter NAO and All-India summer monsoon rainfall and upper-level circulation (Dugam et al. 1997; Yang et al. 2004), as well as between April NAO and peak summer precipitation anomalies over India (Viswambharan and Mohanakumar 2014). Despite the strong heterogeneity at sub-regional scale (Roy 2011), the correlation pattern tends to feature rainfall anomalies of opposite sign between Pakistan and northeastern India (Syed et al. 2012). Figures 3 and 4 (and their higher-resolution counterparts, Figs. S5 and S7) show that the NAO leads to a significant precipitation reduction over north-eastern India during the winter, and to widespread wetter (up to $15 \%$ of the climatology) and colder conditions across the Indo-Gangetic Plain during the summer. ${ }^{4}$ This is particularly relevant for this vastly populated and water-overexploited region

\footnotetext{
${ }^{4}$ Sign and pattern of summer anomalies indicate that temperature is responding to the local precipitation change.
} 


\section{DJFM}
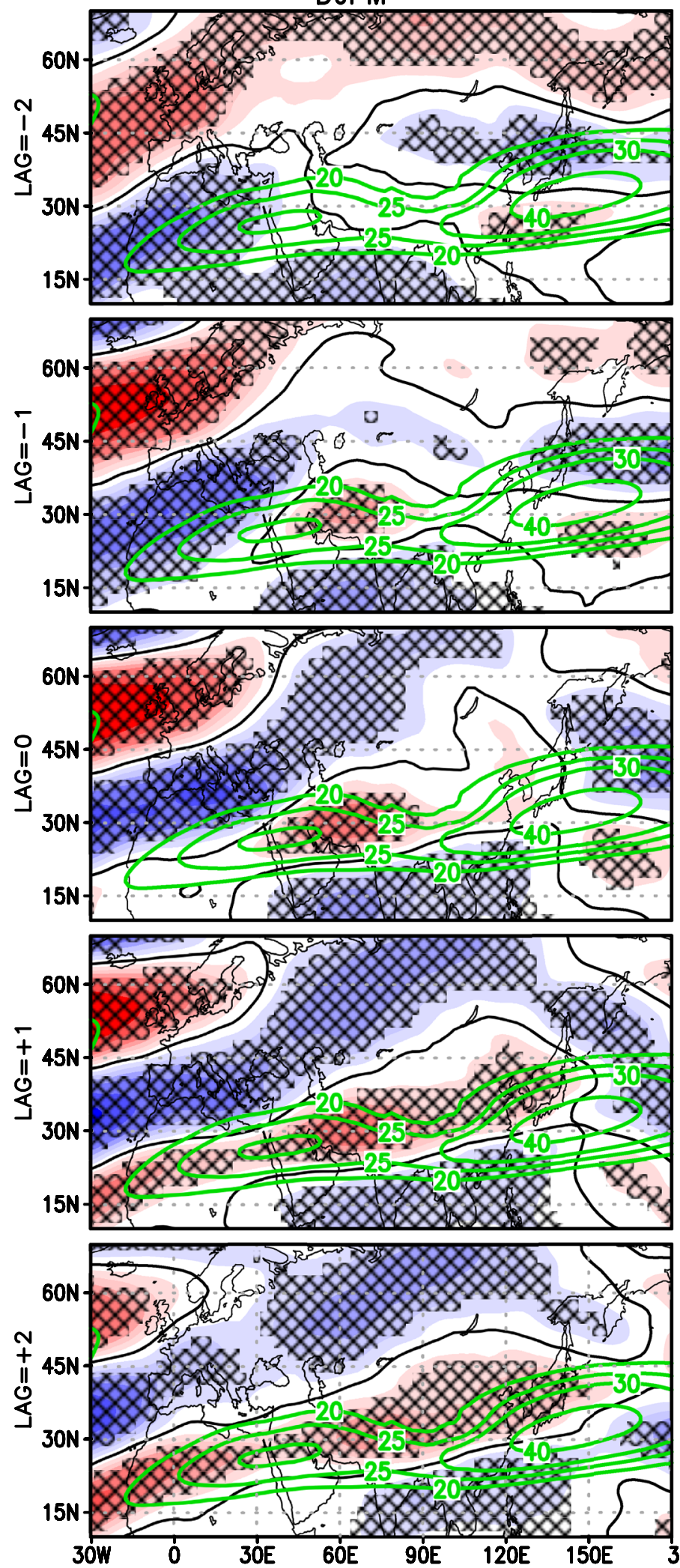

JJA
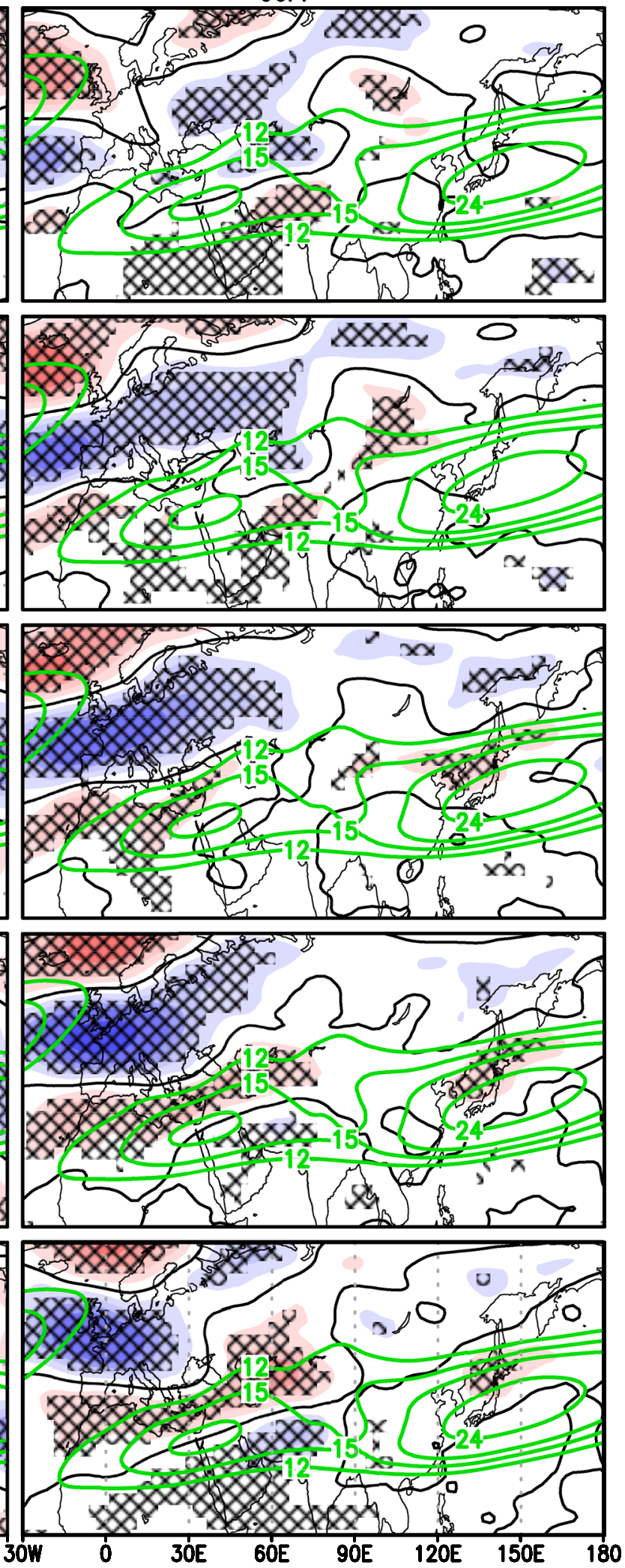

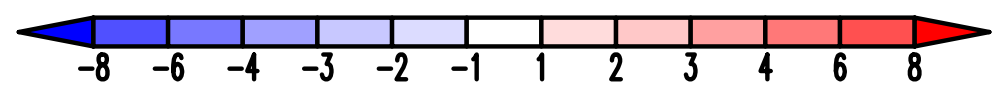


4Fig. 8 Lead-lag regressions of pentad 300-hPa zonal wind $\left(\mathrm{m} \mathrm{s}^{-1}\right)$ on the NAO-EE PC1 for (left) DJFM and (right) JJA from $t=-10$ days $(\mathrm{lag}=-2)$ to $\mathrm{t}=+10$ days $(\mathrm{lag}=+2)$. The black line marks the zero contour, while the green countours represent the 1979-2008 climatological 300-hPa zonal wind $\left(\mathrm{m} \mathrm{s}^{-1}\right)$. The effect of El Niño was removed and the data were filtered at intraseasonal scale before computing the patterns. The cross-hatching marks regions where the correlation exceeds the $95 \%$ confidence level

(MacDonald et al. 2016). Recalling the pattern of NAOrelated circulation anomalies, these surface changes can be dynamically linked to the northward shift of the Asian jet in the winter, deflecting the westerly disturbances, and to the formation of an anticyclonic anomaly over southern China. The latter feature results in increased moisture transport from the north-eastern equatorial Indian Ocean, although its dynamical origin is unclear. Furthermore, Figs. 6 and 7 display a distinct NAO signal centred over Iran and northern Pakistan during the summer consisting of a strengthening mid-upper tropospheric anticyclonic anomaly as part of the southeastward-propagating NAO-related wave train. This pattern, sign reversed, bears a strong similarity to that associated to the 2010 Pakistan flood (see Fig. 4 in Lau and Kim 2012), and together with other findings (e.g., Wright et al. 2014), is suggestive of a potential contribution of the NAO (in its negative phase) to that event. We additionally note that the interaction between the NAO and the Indian Monsoon may not be one-directional, as diabatic heating associated with the monsoon has been associated with significant atmospheric circulation anomalies in the North Atlantic region (Lin 2009).

\section{Concluding remarks}

The subseasonal variability of the NAO and its influence on the large-scale circulation and near-surface climate over East Asia were investigated during both the winter and summer seasons. The analysis was motivated by the need to characterise the NAO's signature in the context of the rapidly-evolving processes inherent to the NAO dynamics and teleconnections. The bulk of the literature has addressed the impact of the NAO on the East Asian winter and summer monsoons at seasonal or longer time scales, while comparatively little attention has been devoted to analysing teleconnections at shorter timescales. Furthermore, a number of studies have focussed on delayed mechanisms (e.g. Gong and Ho 2003; Sung et al. 2006) whose dynamical interpretation is still unclear. Importantly, none of these analyses has taken into account the role of non-stationarity in the NAO's spatial pattern - in particular during its development and decay phase - in modulating its downstream signature.

The analysis is conducted by using the extended EOF technique, which allows us to objectively identify the
Table 1 Non-normalised values of the Wang et al. (2001) EASM index during JJA from $\mathrm{t}=-5$ days $(\operatorname{lag}=-1)$ to $\mathrm{t}=+10$ days $(\mathrm{lag}=+2)$ relative to the peak NAO-EE

\begin{tabular}{lllll}
\hline Lag (pentads) & -1 & 0 & +1 & +2 \\
EASM index $\left(\mathrm{m} \mathrm{s}^{-1}\right)$ & 0 & -0.42 & -0.86 & -0.76 \\
\hline
\end{tabular}

recurrent spatial and temporal NAO patterns, including their nascent and decay structures. This contrasts with the canonical EOF analysis which favours the mature mode, given its larger amplitude and greater contribution to the total variance. The five-pentad sequence of patterns derived from the EEOF can effectively characterise the spatial evolution of the NAO variability at sub-seasonal scales and can be used to provide a detailed portrayal of the downstream link with the East Asian monsoon system. This study therefore provides a link between past analyses of seasonal NAO teleconnections and the underlying higher-frequency variability.

The NAO's spatial pattern at the peak phase is found to closely resemble that derived from EOF analysis, the only appreciable difference being in the percentage of total variance explained. However, the pattern evolution from the nascent to the post-mature NAO phase shows a more complex spatial structure and different temporal characteristics (i.e., longer duration). The NAO generates a significant signature on East Asian climate, playing an important role in modulating regional temperature and precipitation during both the dry and wet seasons. Temperature and precipitation anomalies start developing concurrently with the NAO mature phase, and reach maximum amplitude 5-10 days later. These are shown to be consistently related to the formation of large-scale anomalies in the atmospheric circulation over Asia, at the surface as well as-in an equivalent barotropic structure-in the upper troposphere. The circulation pattern is ultimately associated with mid and high-latitude teleconnections across the Eurasian continent via eastward-propagating quasi-stationary Rossby waves instigated over the North Atlantic and terminating in the northeastern Pacific.

We summarise the rich variety of temperature and precipitation patterns associated with the spatio-temporal evolution of the NAO in Fig. 9. Precipitation and temperature anomalies are averaged over a box located over southeastern China $\left(26^{\circ}-32^{\circ} \mathrm{N}, 112^{\circ}-122^{\circ} \mathrm{E}\right.$, see green boxes in Figs. $\mathrm{S} 5, \mathrm{~S} 7$ ). The selected area features a large NAO signal (cfr. Figs. 3, 4 and S5, S7) and is of utmost social and economic relevance as it encloses various megacities (amongst which Shanghai and Hangzou) and the densely populated Jiangsu province, as well as a large fraction of the intensively cultivated North China Plain and Yangtze River regions. As Fig. 9 illustrates, significant temperature and precipitation anomalies tend to develop during the NAO life-cycle. The impact on precipitation is particularly notable in the drier winter season, when the regressed values are comparatively 
Fig. 9 Lead-lag regressions of APHRODITE pentad precipitation $\left(\mathrm{mm} \mathrm{day}^{-1}\right)$ and 2-m temperature $\left({ }^{\circ} \mathrm{C}\right)$ area-averaged over southeastern China $\left(26^{\circ}-32^{\circ} \mathrm{N}\right.$, $112^{\circ}-122^{\circ} \mathrm{E}$; see Figs. S5, S7) on the NAO-EE PC1 for (left) DJFM and (right) JJA and from $\mathrm{t}=-5$ days $(\operatorname{lag}=-1)$ to $\mathrm{t}=+10$ days $(\operatorname{lag}=+2)$. The effect of El Niño was removed and the data were filtered at intraseasonal scale before computing the values. The black dots mark where the correlation exceeds the $90 \%$ confidence level
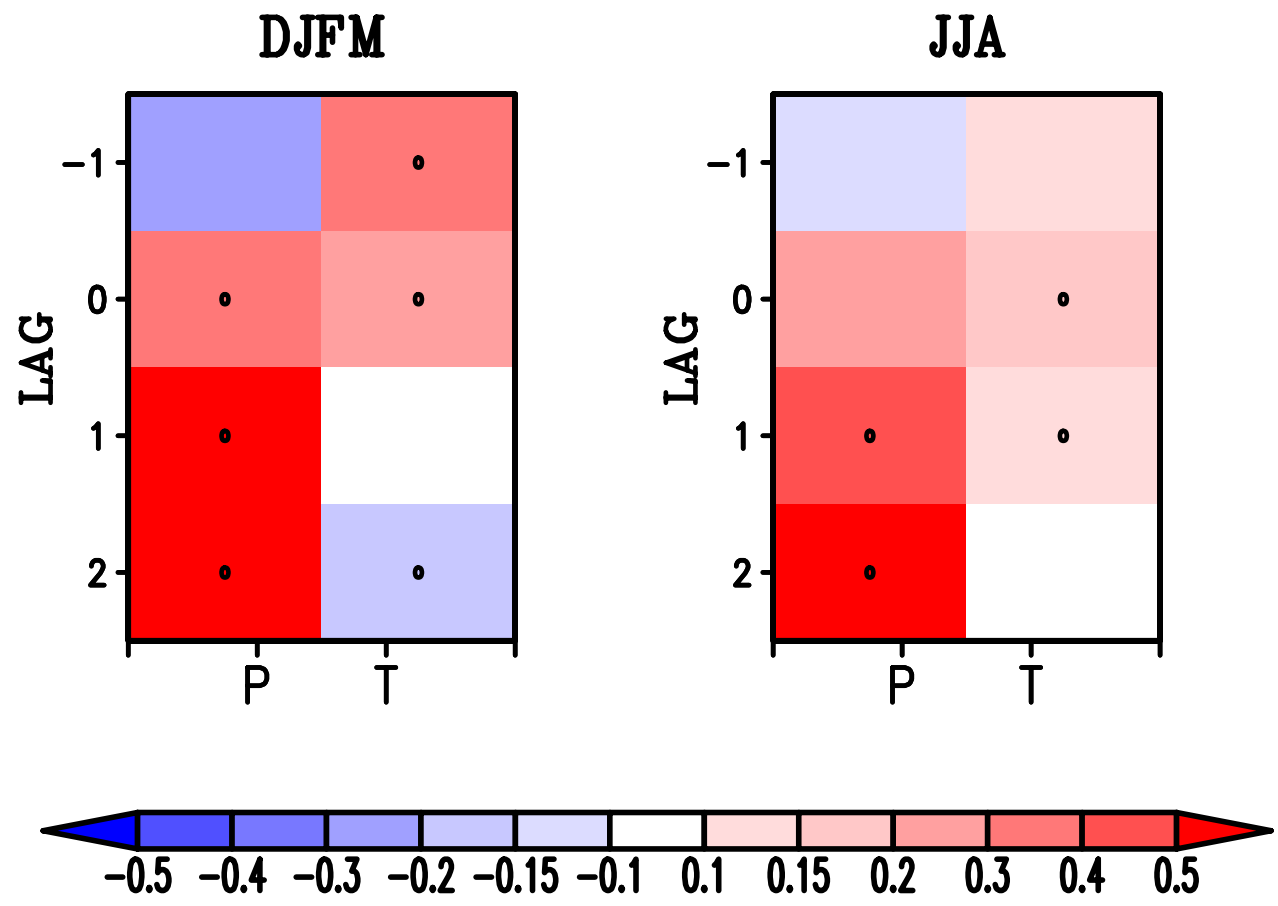

large relative to the climatological precipitation rates in the region. More generally, the figure highlights the non-stationary nature of the link, whose magnitude-and even signcan change over the NAO's life-cycle. Some of the links we find, such as the summertime strong positive precipitation signal over the Yangtze River basin for a positive NAO, are very different from the patterns previously highlighted in the literature using a stationary description of the NAO. This has wider implications, as the potentially important role of internal climate variability in modulating the climate of this key region is critical for a more accurate assessment of the magnitude of anthropogenic-driven changes and, ultimately, to enable the development of cost-effective adaptation policies.

The above findings and the EEOF-based approach also have important implications for the sub-monthly predictability of the NAO impact on Asian climate. In particular, the appreciation of the remotely-driven intraseasonal temperature and precipitation variability is crucial for addressing events such as flash droughts and floods. The first is a relatively recent concept (Senay et al. 2008) referring to brief periods characterised by warm surface temperatures and a rapid decrease in soil moisture, although later studies have discussed flash droughts driven by precipitation deficits (Mo et al. 2016). The second is a common occurrence in China, often associated with intense rainfall over relatively short periods (e.g. Zhou et al. 2013). Our results therefore provide a valuable complement to the rapidly advancing understanding of the seasonal, interannual and longer-timescale remote drivers of East Asian climate. Furthermore, this study provides a powerful toolkit to evaluate the skill of climate models in reproducing the NAO-driven seasonal and sub-seasonal patterns over East Asia.

Acknowledgements G. Messori acknowledges the support of a grant from the Department of Meteorology of Stockholm University, of Vetenskapsrådet under contract 2016-03724_VR and of the UK-China Research and Innovation Partnership Fund through the Met Office Climate Science for Service Partnership (CSSP) China as part of the Newton Fund. Both authors wish to thank Dr Bin Guan (JPL/NASA) for his technical advice on using the EEOF code and acknowledge the E-OBS dataset from the EU-FP6 project ENSEMBLES (http://ensem bles-eu.metoffice.com) and the data providers in the ECA\&D project (http://www.ecad.eu).

Open Access This article is distributed under the terms of the Creative Commons Attribution 4.0 International License (http://creativeco mmons.org/licenses/by/4.0/), which permits unrestricted use, distribution, and reproduction in any medium, provided you give appropriate credit to the original author(s) and the source, provide a link to the Creative Commons license, and indicate if changes were made.

\section{References}

Barnes EA, Hartmann DL (2010) Dynamical feedbacks and the persistence of the NAO. J Atmos Sci 67:851-865

Baxter S, Nigam S (2013) A subseasonal teleconnection analysis: PNA development and its relationship to the NAO. J Clim 26:6733-6741

Branstator G (2002) Circumglobal teleconnections, the jet stream waveguide, and the North Atlantic Oscillation. J Clim 15:1893-1910

Chang CP (ed) (2004) East Asian monsoon. World Scientific, Singapore, p. 564 
Chang CZ, Wang Z, Hendon H (2006) The Asian winter monsoon. Wang B (ed), The Asian monsoon, Springer, New York, pp 89-127

Compo GP, Sardeshmukh PD (2010) Removing ENSO-related variations from the climate record. J Clim 23:1957-1978

Dee D et al (2011) The ERA-Interim reanalysis: Configuration and performance of the data assimilation system. Q J R Metrol Soc 137:553-597

Ding Y, Chan J (2005) The East Asian summer monsoon: an overview. J Met Atmos Phys 89:117-142

Dugam SS, Kakade SB, Verma RK (1997) Interannual and long-term variability in the North Atlantic Oscillation and Indian summer monsoon rainfall. Theor Appl Climatol 58:21-29

Enomoto T, Hoskins BJ, Matsuda Y (2003) The formation mechanism of the Bonin high in August. Q J R Metrol Soc 129:157-178

Fan K, Tian BQ, Wang HJ (2015) New approaches for the skillful prediction of the winter North Atlantic Oscillation based on coupled dynamic climate models. Int J Climatol. https://doi.org/10.1002/ joc. 4330

Feldstein SB (2000) The timescale, power spectra, and climate noise properties of teleconnection patterns. J Clim 13:4430-4440

Feldstein SB (2003) The dynamics of NAO teleconnection pattern growth and decay. Q J R Metrol Soc 129:901-924

Feng J, Wang L, Chen W (2014) How does the East Asian summer monsoon behave in the decaying phase of El Niño during different PDO phases? J Clim 27:2682-2698

Folland CK et al (2009) The summer North Atlantic oscillation: past, present, and future. J Clim 22:1082-1103

Franzke C, Woollings T (2011) On the persistence and predictability properties of North Atlantic climate variability. J Clim 24:466-472

Fu C, Zeng Z (2005) Correlations between North Atlantic Oscillation Index in winter and eastern China Flood/Drought Index in summer in the last 530 years. Chin Sci Bull 50:2505-2516

Gong DY, Ho CH (2003) Arctic oscillation signals in the East Asian summer monsoon. J Geophys Res 108:4066. https://doi. org/10.1029/2002JD002193 D2.

Gong DY, Wang SW, Zhu JH (2001) East Asian winter monsoon and Arctic oscillation. Geophys Res Lett 28:2073-2076

Gong DY, Yang J, Kim SJ, Gao Y, Guo D, Zhou T, Hu M (2011) Spring Arctic Oscillation-East Asian summer monsoon connection through circulation changes over the western North Pacific. Clim Dyn 37:2199-2216

$\mathrm{Gu}$ W et al (2009) Interdecadal unstationary relationship between NAO and east China's summer precipitation patterns. Geophys Res Lett 36:L13702. https://doi.org/10.1029/2009GL038843

Haylock MR et al (2008) A European daily high-resolution gridded dataset of surface temperature and precipitation. J Geophys Res 113:D20119. https://doi.org/10.1029/2008JD10201

Huang R, Chen J, Wang L, Lin Z (2012) Characteristics, processes, and causes of the spatio-temporal variabilities of the East Asian monsoon system. Adv Atmos Sci 29:910-942

Hurrell JW (1995) Decadal trends in the North Atlantic Oscillation: regional temperatures and precipitation. Science 269:676-679

Hurrell JW (1996) Influence of variations in extratropical wintertime teleconnections on Northern Hemisphere temperature. Geophys Res Lett 23:665-668

Hurrell JW, Kushnir Y, Ottersen G, Visbeck M (2003) An overview of the North Atlantic Oscillation. The North Atlantic Oscillation: Climatic Significance and Environmental Impact, Geophys. Monogr, vol 134, Amer. Geophys. Union, pp 1-35

Jeong JH, Ho CH (2005) Changes in occurrence of cold surges over east Asia in association with Arctic Oscillation. Geophys Res Lett 32:L14704. https://doi.org/10.1029/2005GL023024
Ju J, Junmei L, Jie C, Juzhang R (2005) Possible impacts of the Arctic Oscillation on the interdecadal variation of summer monsoon rainfall in East Asia. Adv Atmos Sci 22:39-48

Keeley SPE, Sutton R, Shaffrey L (2009) Does the North Atlantic oscillation show unusual persistence on intraseasonal timescales? Geophys Res Lett. https://doi.org/10.1029/2009GL040367

Kubota H, Kosaka Y, Xie SP (2016) A 117-year long index of the Pacific-Japan pattern with application to interdecadal variability. Int J Climatol 36:1575-1589. https://doi.org/10.1002/joc.4441

Kucharski F et al (2009) A Gill-Matsuno-type mechanism explains the tropical Atlantic influence on African and Indian monsoon rainfall. Q J R Metrol Soc 135:569-579

Lau KM, Kim KM (2012) The 2010 Pakistan Flood and Russian Heat wave: teleconnection of hydrometeorological extremes. J Hydrometeorol 13:392-403

Lau KM, Kim KM, Yang S (2000) Dynamical and boundary forcing characteristics of regional components of Asian summer monsoon. J Clim 13:2461-2482

Li J, Wang XL (2003) A new North Atlantic Oscillation index and its variability. Adv Atmos Sci 20:661-676

Li J, Yu R, Zhou T (2008) Teleconnection between NAO and climate downstream of the Tibetan Plateau. J Clim 21:4680-4690

Li J, Fan K, Zhou L (2015) Links between the late wintertime North Atlantic Oscillation and springtime vegetation growth over Eurasia. Clim Dyn 46:987-1000

Lin H (2009) Global extratropical response to diabatic heating variability of the Asian summer monsoon. J Atmos Sci 66:2697-2713

Lin JS, Wu B, Zhou TJ (2016) Is the interdecadal circumglobal teleconnection pattern excited by the Atlantic multidecadal Oscillation? Atmos Ocean Sci Lett 9:451-457

Linderholm HW et al (2011) Interannual teleconnections between the summer North Atlantic Oscillation and the East Asian summer monsoon. J Geophys Res 116:D13107. https://doi. org/10.1029/2010JD015235

Liu X, Yin ZY (2001) Spatial and temporal variation of summer precipitation over the Eastern Tibetan Plateau and the North Atlantic Oscillation. J Clim 14:2896-2909

Lu R-Y, Oh JH, Kim BJ (2002) A teleconnection pattern in upperlevel meridional wind over the North African and Eurasian continent in summer. Tellus A 54:44-55

Lu R, Dong B, Ding H (2006) Impact of the Atlantic Multidecadal Oscillation on the Asian summer monsoon. Geophys Res Lett 33:L24701. https://doi.org/10.1029/2006GL027655

MacDonald AM et al (2016) Groundwater quality and depletion in the Indo-Gangetic Basin mapped from in situ observations. Nat Geosci 9:762-766

McCabe GJ, Palecki MA, Betancourt JL (2004) Pacific and Atlantic Ocean influences on multidecadal drought frequency in the United States. Proc Natl Acad Sci 101:4136-4141

Mo K, Center CP, Lettenmaier DP (2016) Precipitation deficit flash droughts over the United States. J Hydrometrol 17:1169-1184

Nigam S, Baxter S (2015) Teleconnections. In: North GR, Pyle J, Zhang F (eds) Encyclopedia of Atmospheric Sciences, vol 3, 2nd edn. Academic Press, Elsevier Science, London, pp 90-109

Ogi M, Tachibana Y, Yamazaki K (2003) Impact of the wintertime North Atlantic Oscillation (NAO) on the summertime atmospheric circulation. Geophys Res Lett 30:1704. https://doi. org/10.1029/2003GL017280

Plumb RA (1985) On the three-dimensional propagation of stationary waves. J Atmos Sci 42:217-229

Portis DH, Walsh JE, El Hamly M, Lamb PJ (2001) Seasonality of the North Atlantic Oscillation. J Clim 14:2069-2078

Roy SS (2011) The role of the North Atlantic Oscillation in shaping regional scale peak seasonal precipitation across the Indian Subcontinent. Earth Interact 15:1-13 
Senay GB, Budde MB, Brown JF, Verdin JP (2008) Mapping flash drought in the US: Southern Great Plains. In: 22nd Conference on Hydrology. AMS, New Orleans, LA

Song F, Zhou T (2015) The Crucial role of internal variability in modulating the decadal variation of the East Asian Summer Monsoon-ENSO Relationship during the twentieth century. J Clim 28:7093-7107

Song J, Li C, Zhou W (2014) High and low latitude types of the downstream influences of the North Atlantic Oscillation. Clim Dyn 42:1097-1111

Sun J, Wang H (2012) Changes of the connection between the summer North Atlantic Oscillation and the East Asian summer rainfall. J Geophys Res 117:D08110. https://doi.org/10.1029/2012JD017482

Sun J, Wang H, Yuan W (2008) Decadal variations of the relationship between the summer North Atlantic Oscillation and middle East Asian air temperature. J Geophys Res 113:D15107. https://doi. org/10.1029/2007JD009626

Sung MK et al (2006) A possible impact of the North Atlantic Oscillation on the East Asian summer monsoon precipitation. Geophys Res Lett 33:L21713. https://doi.org/10.1029/2006GL027253

Sung MK, Lim GH, Kug JS (2010) Phase asymmetric downstream development of the North Atlantic Oscillation and its impact on the East Asian winter monsoon. J Geophys Res 115:D09105. https ://doi.org/10.1029/2009JD013153

Sung MK, Lim GH, Kug JS, An SI (2011) A linkage between the North Atlantic Oscillation and its downstream development due to the existence of a blocking ridge. J Geophys Res 116:D11107. https ://doi.org/10.1029/2010JD015006

Syed FS, Yoo JH, Kornich H, Kucharski F (2012) Extratropical influences on the interannual variability of South Asian monsoon. Clim Dyn 38:1661-1674

Takaya K, Nakamura H (2001) A formulation of a phase-independent wave activity flux for stationary and migratory quasigeostrophic eddies on a zonally varying basic flow. J Atmos Sci 58:608-627

Tian BQ, Fan K (2012) Relationship between the late spring NAO and summer extreme precipitation frequency in the middle and lower reaches of the Yangtze River. Atmos Ocean Sci Lett 5:455-460

Tian BQ, Fan K (2015) A skillful prediction model for winter NAO based on Atlantic sea surface temperature and Eurasian snow cover. Weather Forecasting. https://doi.org/10.1175/WAF-D-1400100.1

Viswambharan N, Mohanakumar K (2014) Modulation of Indian summer monsoon through northern and southern hemispheric extratropical oscillations. Clim Dyn 43:925-938

Wang B, Fan Z (1999) Choice of South Asian summer monsoon indices. Bull Am Meteorol Soc 80:629-638

Wang B, Wu R, Lau KM (2001) Interannual variability of the Asian summer monsoon: contrasts between the Indian and the Western North Pacific-East Asian Monsoons. J Clim 14:4073-4090

Wang B, Clemens SC, Liu P (2003) Contrasting the Indian and East Asian monsoons: implications on geologic timescales. Mar Geol 201:5-21

Watanabe M (2004) Asian jet waveguide and a downstream extension of the North Atlantic Oscillation. J Clim 17:4674-4691

Weare BC, Nasstrom JS (1982) Examples of extended empirical orthogonal function analyses. Mon Weather Rev 110:481-485

Wright CK, de Beurs KM, Henebry GM (2014) Land surface anomalies preceding the 2010 Russian heat wave and a link to the North Atlantic oscillation. Environ Res Lett 9:124015

Wu BY, Huang RH (1999) Effects of the extremes in the North Atlantic Oscillation on East Asia winter monsoon. Chin J Atmos Sci 23:641-651 (in Chinese)

Wu B, Wang J (2002) Winter Arctic oscillation, siberian high and East Asian Winter Monsoon. Geophys Res Lett 29:1897. https://doi. org/10.1029/2002GL015373
Wu R, Hu ZZ, Kirtman BP (2003) Evolution of ENSO-related rainfall anomalies in East Asia. J Clim 16:3742-3758

Wu Z, Wang B, Li J, Jin FF (2009) An empirical seasonal prediction model of the East Asian summer monsoon using ENSO and NAO. J Geophys Res 114:D18120. https://doi.org/10.1029/2009J D011733

Wu Z et al (2012) Possible effects of the North Atlantic Oscillation on the strengthening relationship between the East Asian summer monsoon and ENSO. Int J Climatol 32:794-800

Wu B, Lin J, Zhou T (2016a) Interdecadal circumglobal teleconnection pattern during boreal summer. Atmos Sci Lett 17:446-452

Wu Q, Yan Y, Chen D (2016b) Seasonal prediction of East Asian monsoon precipitation: skill sensitivity to various climate variabilities. Int J Climatol 36:324-333

Xiao M, Zhang Q, Singh VP (2015) Influences of ENSO, NAO, IOD and $\mathrm{PDO}$ on seasonal precipitation regimes in the Yangtze River basin, China. Int J Climatol 35:3556-3567

Xie P, Arkin PA (1996) Analyses of global monthly precipitation using gauge observations, satellite estimates, and numerical model predictions. J Clim 9:840-858

Xin X, Yu R, Zhou T, Wang B (2006) Drought in late spring of South China in recent decades. J Clim 19:3197-3206

Xin X, Zhou T, Yu R (2010) Increased Tibetan Plateau snow depth: An indicator of the connection between enhanced winter NAO and late-spring tropospheric cooling over East Asia. Adv Atmos Sci 27:788-794

Xu HM, He JH, Dong M (2001) Interannual variability of the Meiyu onset and its association with North Atlantic Oscillation and SSTA over the North Atlantic. Acta Meteorol Sin 59:694-706. https://doi.org/10.11676/qxxb2001.073 (in Chinese)

Xu HL, Li JP, Feng J, Mao JY (2012) The asymmetric relationship between the winter NAO and the precipitation in southwest China. Acta Meteorol Sin 70:1276-1291 (in Chinese)

Xu HL, Feng J, Sun C (2013) Impact of preceding summer North Atlantic Oscillation on early autumn precipitation over Central China. Atmos Ocean Sci Lett 6:417-422

Xu ZQ, Fan K, Wang HJ (2015) Decadal variation of summer precipitation over China and associated atmospheric circulation after the late 1990s. J Clim 28:4086-4106

Yang S, Lau KM, Kim KM (2002) Variations of the East Asian jet stream and Asian-Pacific-American winter climate anomalies. J Clim 15:306-325

Yang S et al (2004) Upstream Subtropical Signals Preceding the Asian Summer Monsoon Circulation. J Clim 17:4213-4229

Yasutomi N, Hamada A, Yatagai A (2011) Development of a longterm daily gridded temperature dataset and its application to rain/ snow discrimination of daily precipitation. Glob Environ Res $15: 165-172$

Yatagai A et al (2012) APHRODITE: Constructing a long-term daily gridded precipitation dataset for Asia based on a dense network of rain gauges. Bull Am Metrol Soc 93:1401-1415

Yu R, Zhou T (2004) Impacts of winter-NAO on March cooling trends over subtropical Eurasia continent in the recent half century. Geophys Res Lett 31:L12204

Yuan W, Sun JQ (2009) Enhancement of the summer North Atlantic Oscillation influence on Northern Hemisphere air temperature. Adv Atmos Sci 26:1209-1214

Zhang Y, Kuang X, Guo W, Zhou T (2006) Seasonal evolution of the upper-tropospheric westerly jet core over East Asia. Geophys Res Lett 33:L11708. https://doi.org/10.1029/2006GL026377

Zheng F, Li J, Li Y, Zhao S, Deng D (2016) Influence of the Summer NAO on the Spring-NAO-based predictability of the East Asian summer monsoon. J Clim 55:1459-1476

Zhou BT (2013) Weakening of winter North Atlantic Oscillation signal in spring precipitation over southern China. Atmos Ocean Sci Lett 6:248-252 
Zhou T, Gong D, Li J, Li B (2009) Detecting and understanding the multi-decadal variability of the East Asian Summer Monsoon: Recent progress and state of affairs. Meteorol Z 18:455-467

Zhou T et al (2013) The 2012 North China floods: Explaining an extreme rainfall event in the context of a longer-term drying tendency. Bull Am Meteorol Soc 94:S49
Zuo JQ et al (2016) Interdecadal variations in the relationship between the winter North Atlantic Oscillation and temperature in southcentral China. J Clim 29:7477-7493 